\title{
Palladium-catalyzed carbamate-directed regioselective halogenation: A route to halogenated anilines
}

Firouz Matloubi Moghaddam,*a ${ }^{\text {Ghazal Tavakoli, }}{ }^{a}$ Borna Saeednia ${ }^{a}$, Peter Langer ${ }^{b}$ and Behzad Jafari ${ }^{\text {b }}$

Laboratory of Organic Synthesis and Natural Products, Department of Chemistry, Sharif University of Technology, Azadi Street, PO Box 111559516, Tehran, Iran.

${ }^{b}$ Universität Rostock, Institut für Chemie, Albert-Einstein-Str. 3a, 18059 Rostock, Germany

E-mail:matloubi@sharif.edu

\section{Table of Contents}

NMR spectra of starting materials and final products 

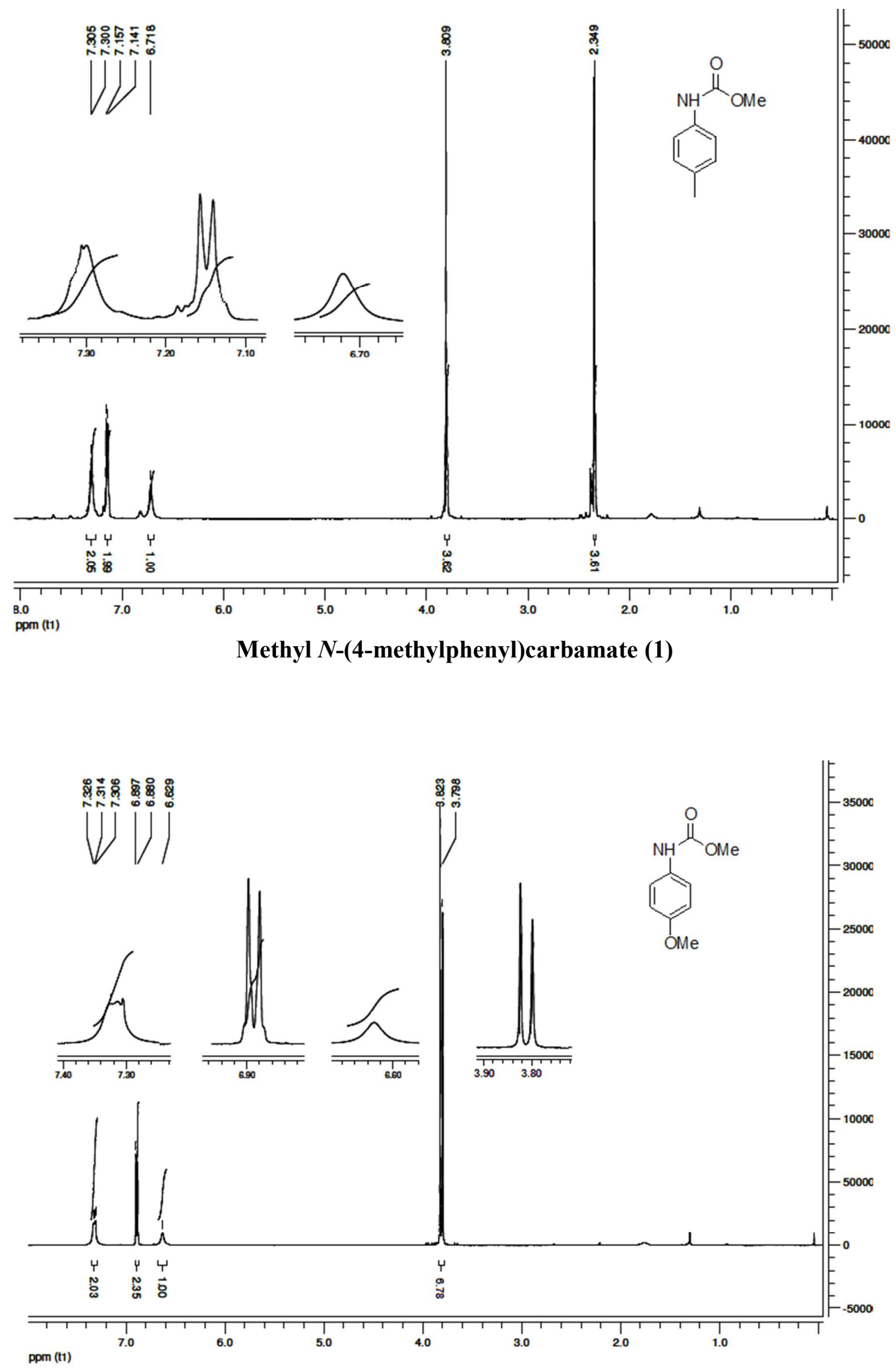

Methyl N-(4-methoxyphenyl)carbamate (2) 


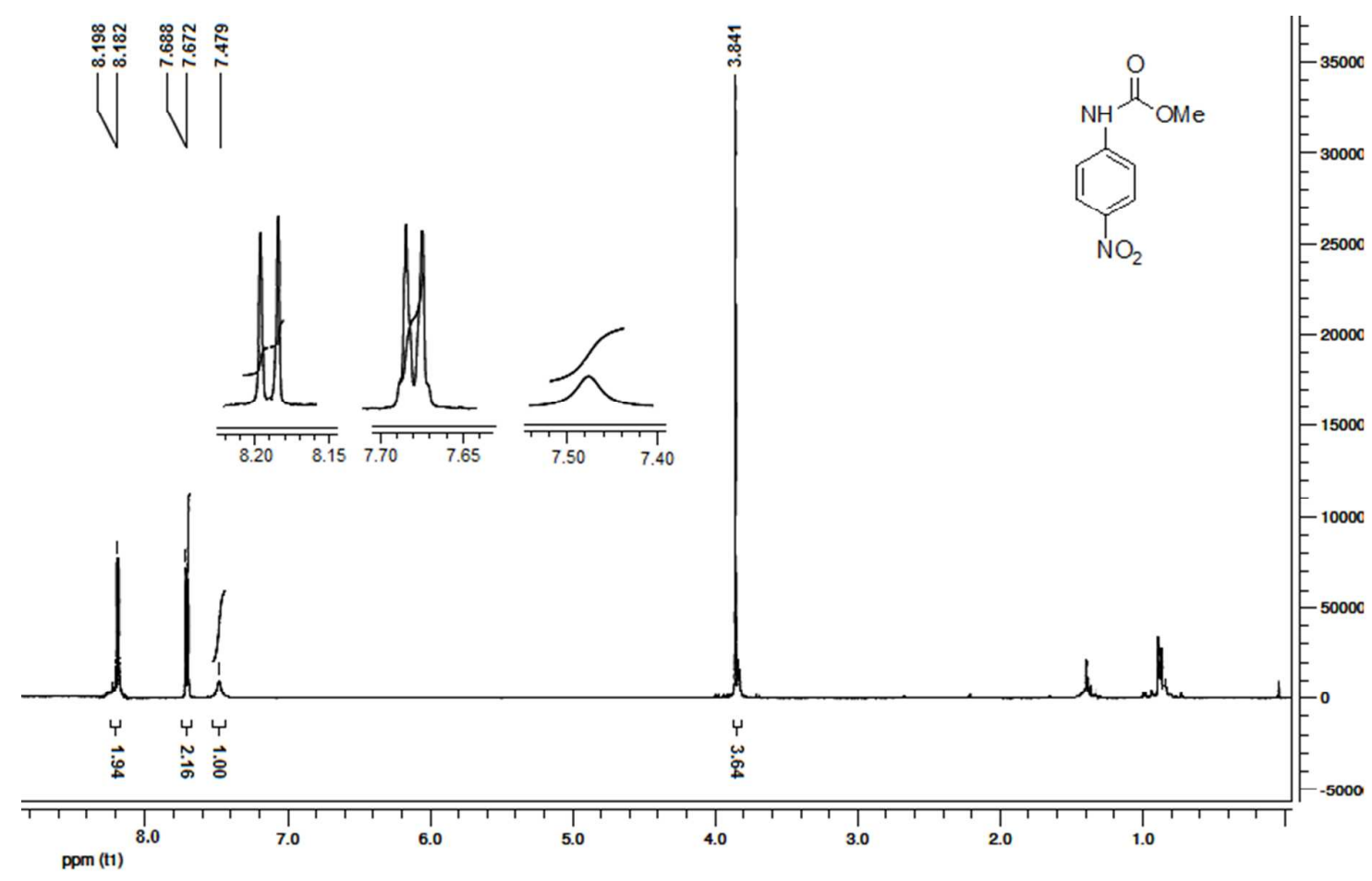

Methyl N-(4-nitrophenyl)carbamate (3)

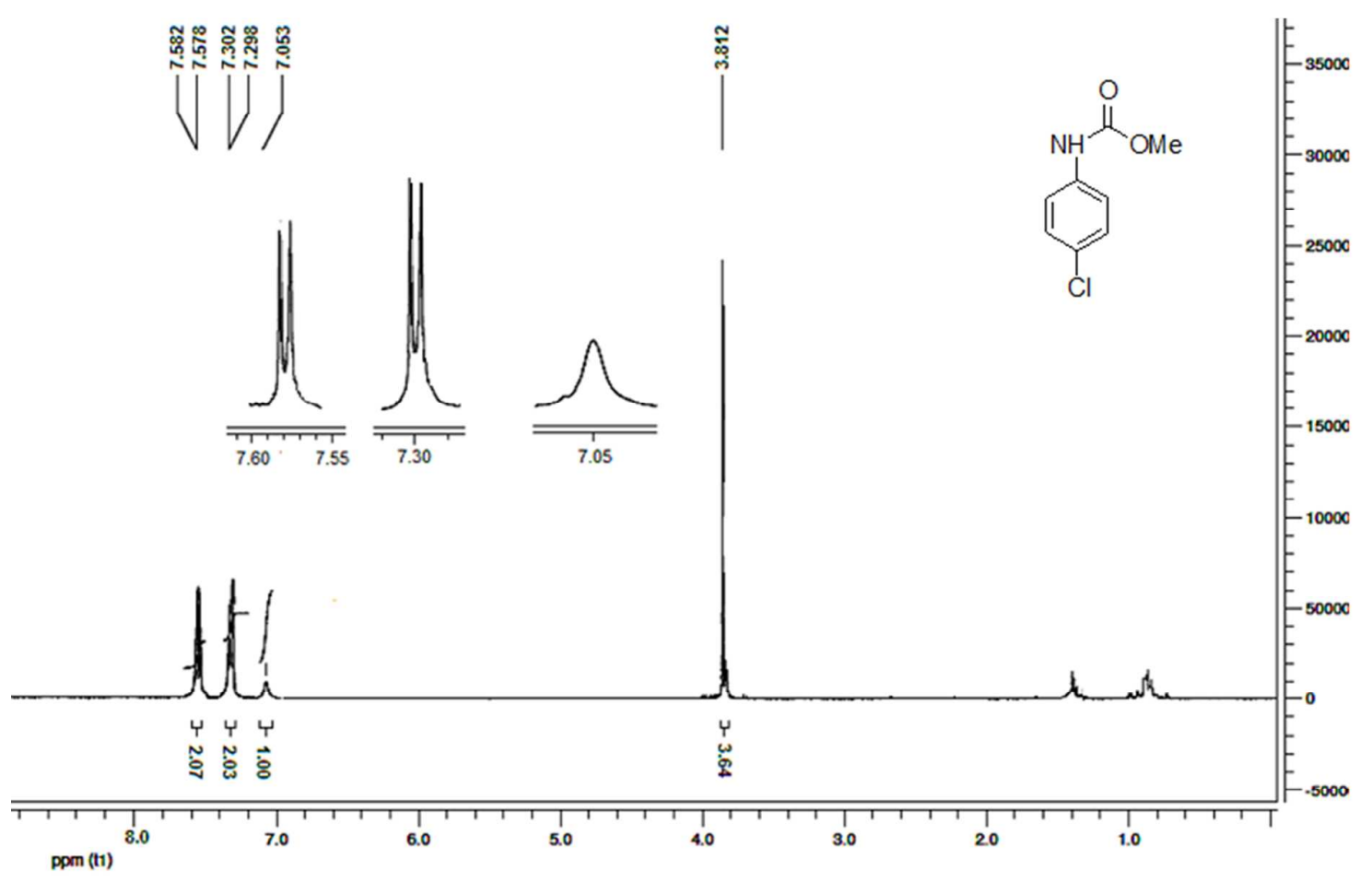

Methyl N-(4-chlorophenyl)carbamate (4) 


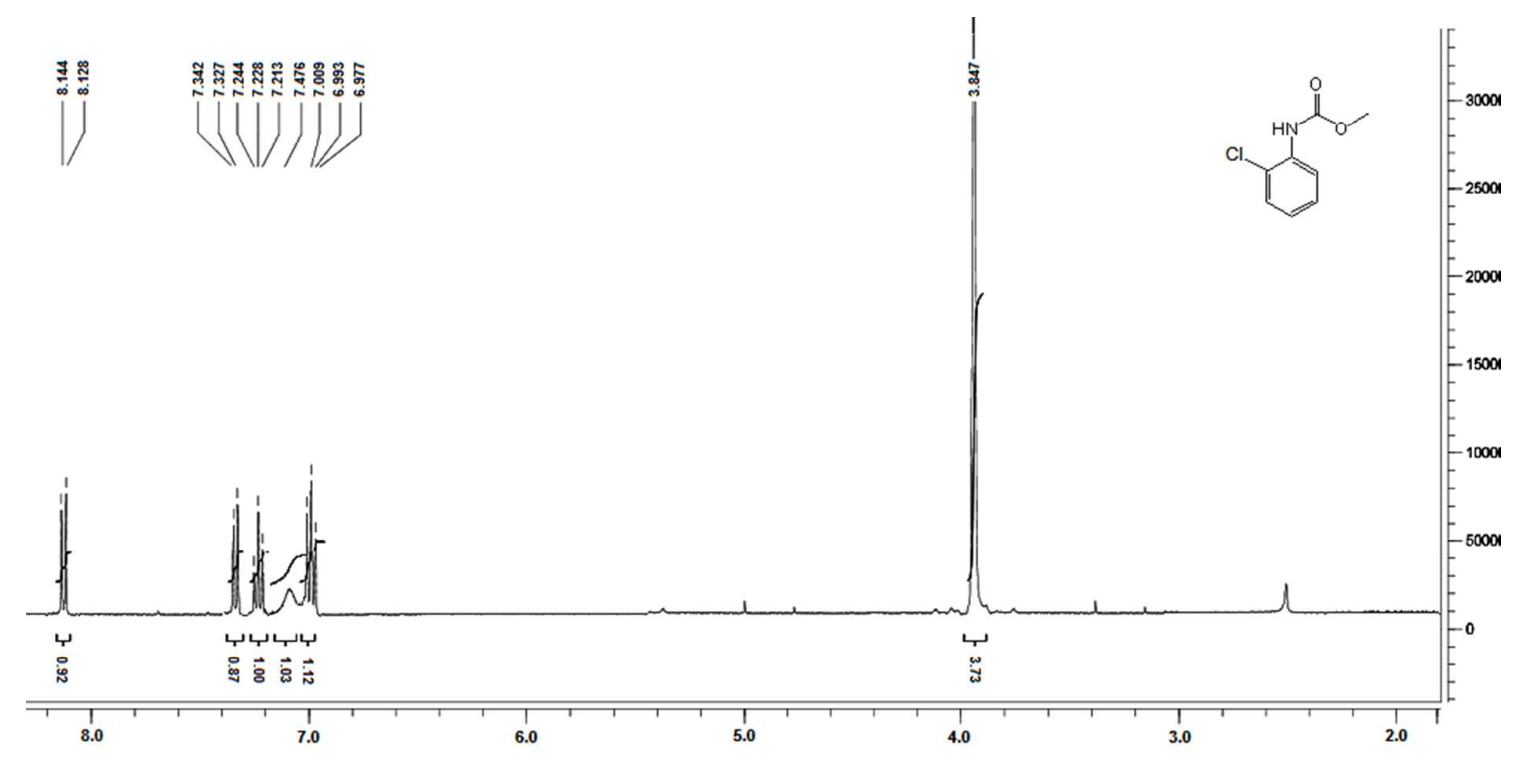

Methyl N-(2-chlorophenyl)carbamate (5)

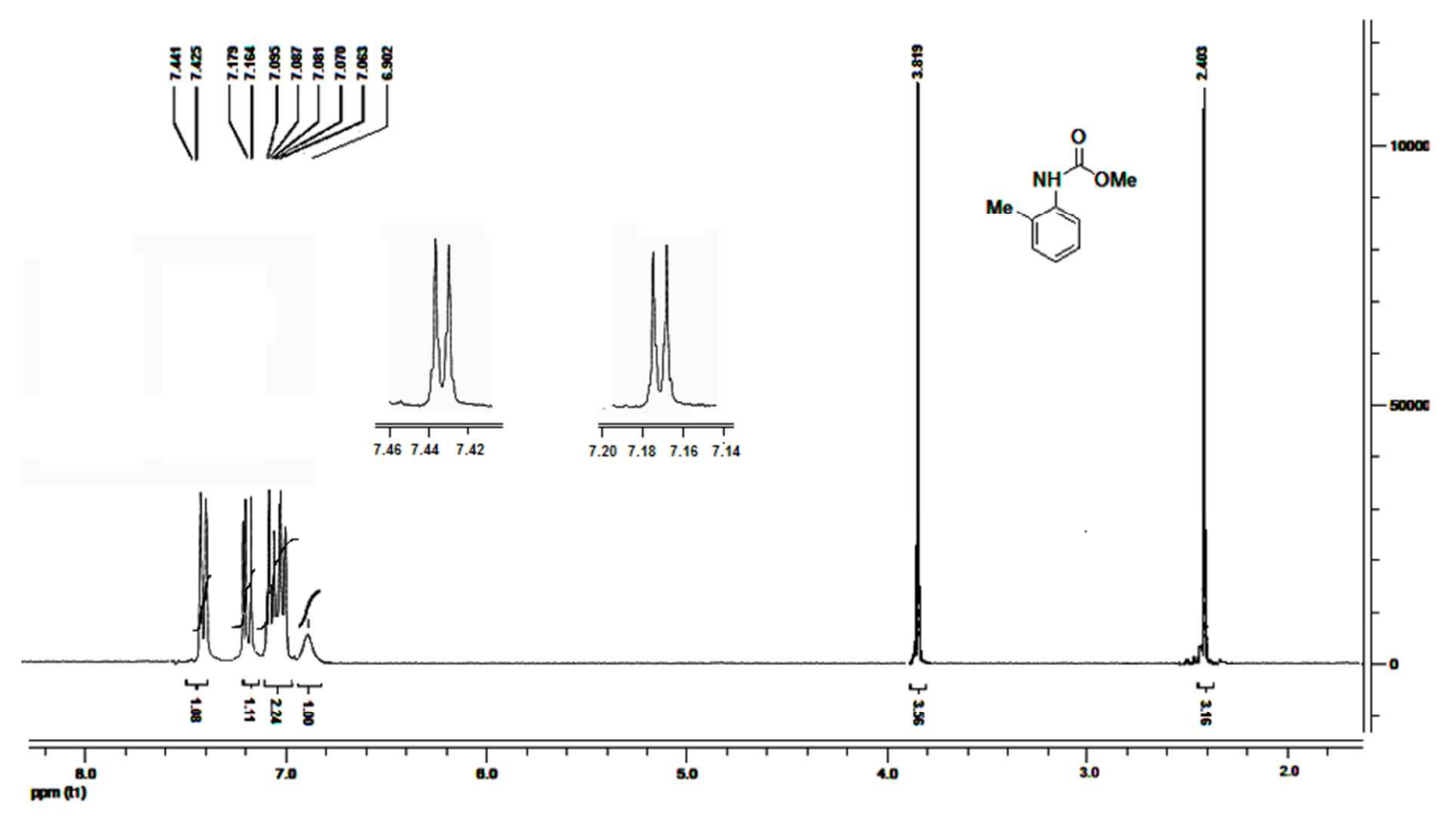

Methyl N-(2-methylphenyl)carbamate (6) 


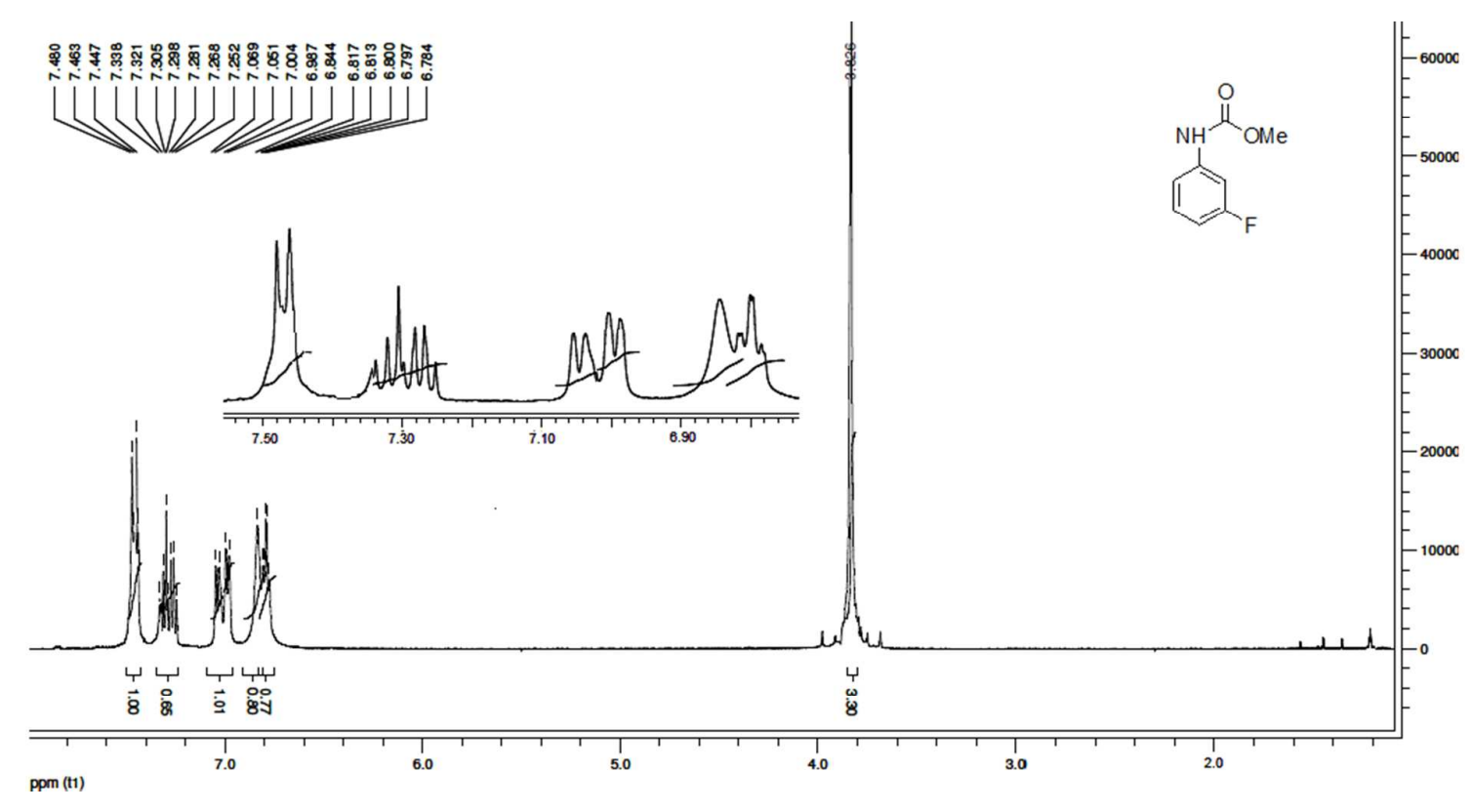

\section{Methyl $N$-(3-fluorophenyl)carbamate (7)}

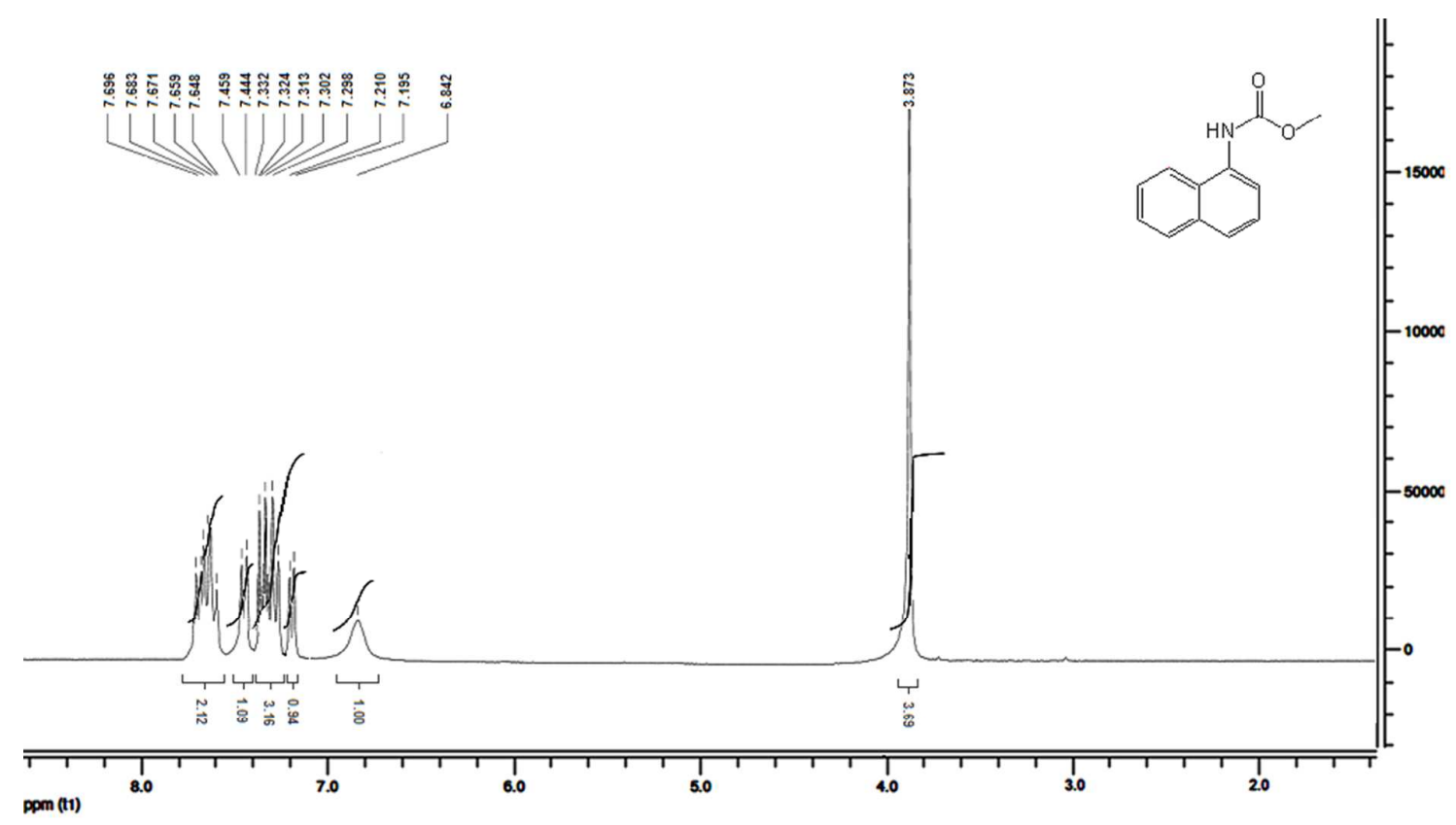

Methyl N-(1-naphthyl)carbamate (8) 


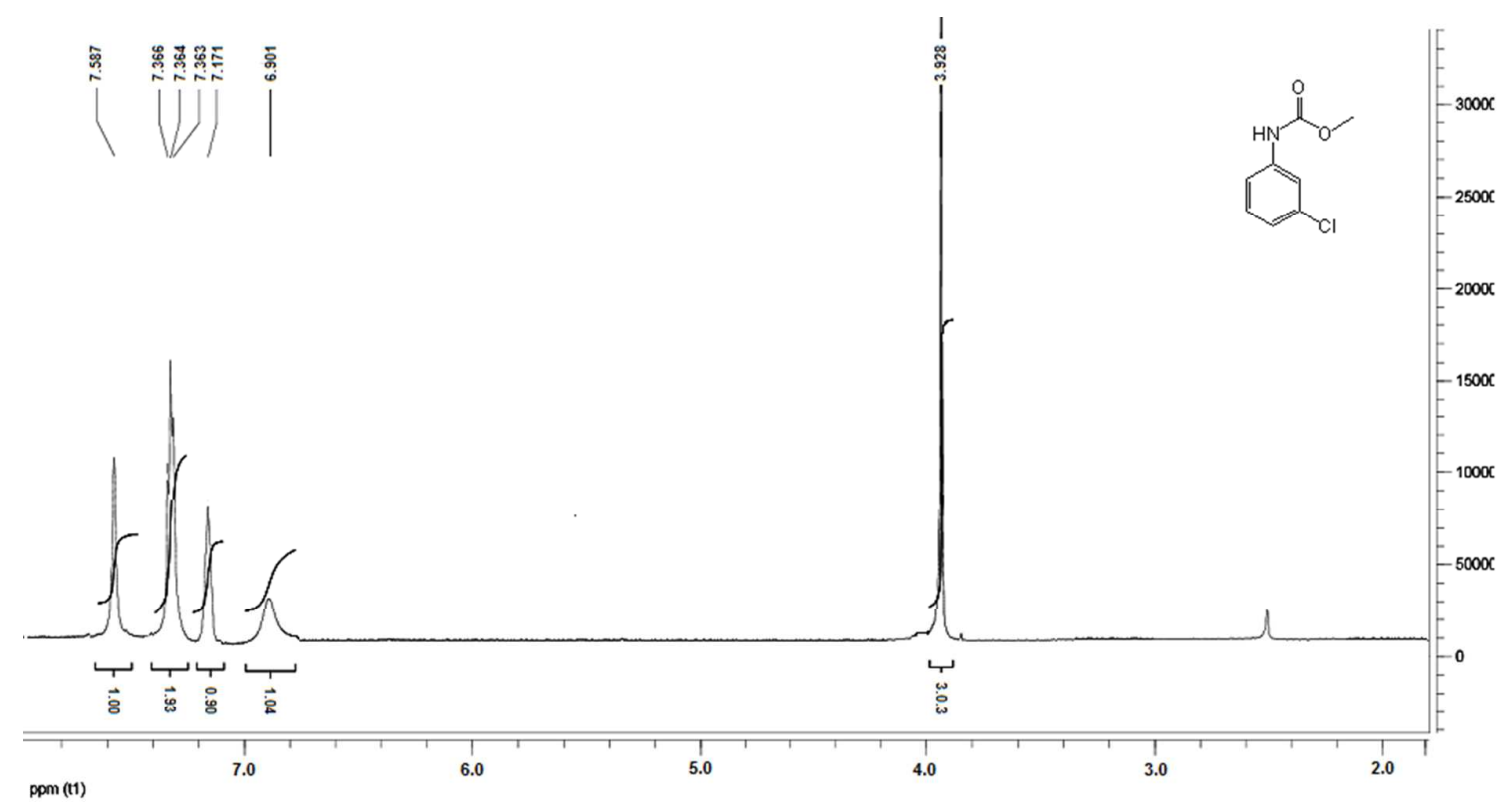

Methyl N-(3-chlorophenyl)carbamate (9)

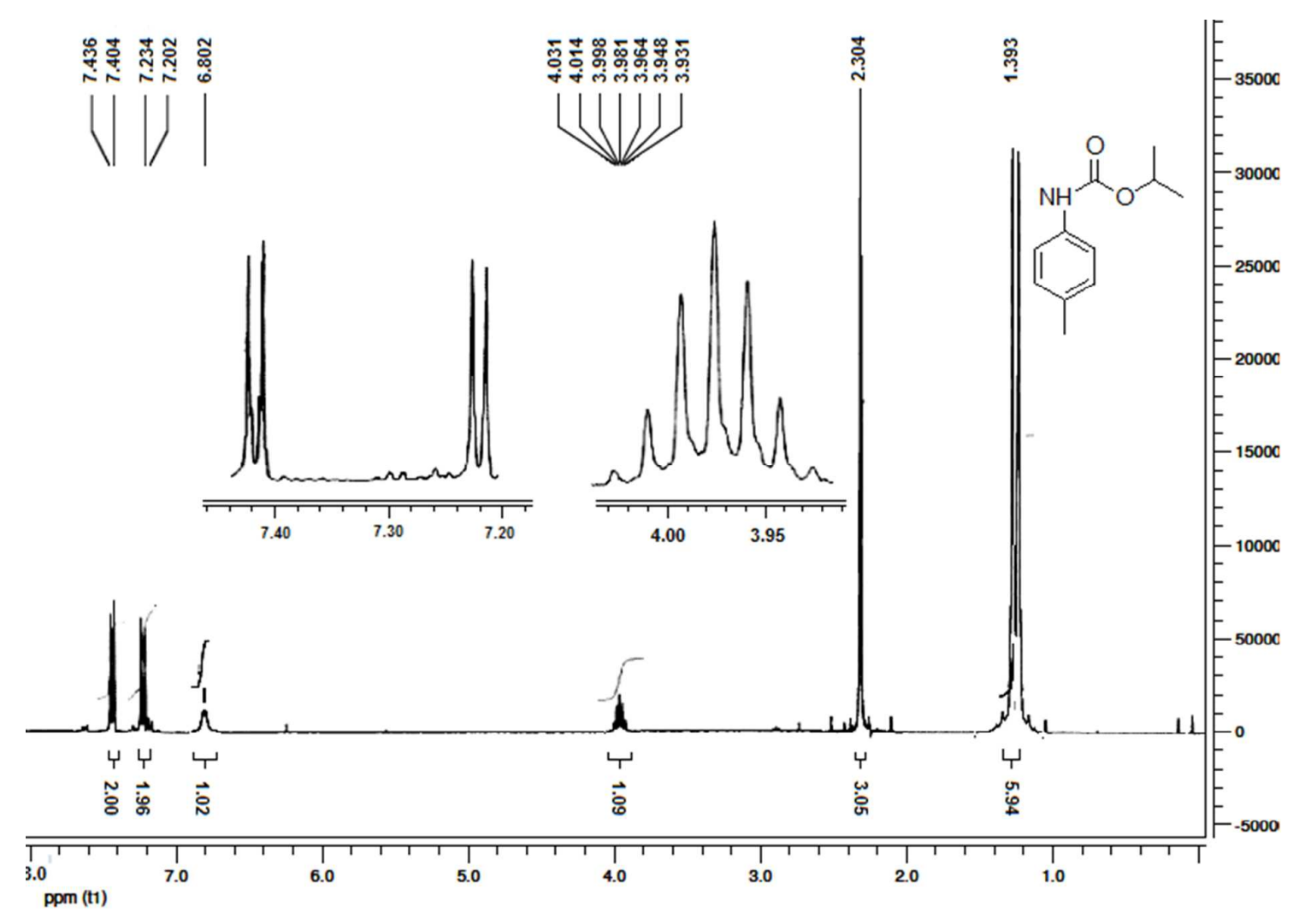

isopropyl $\mathrm{N}$-(4-methylphenyl)carbamate (10) 


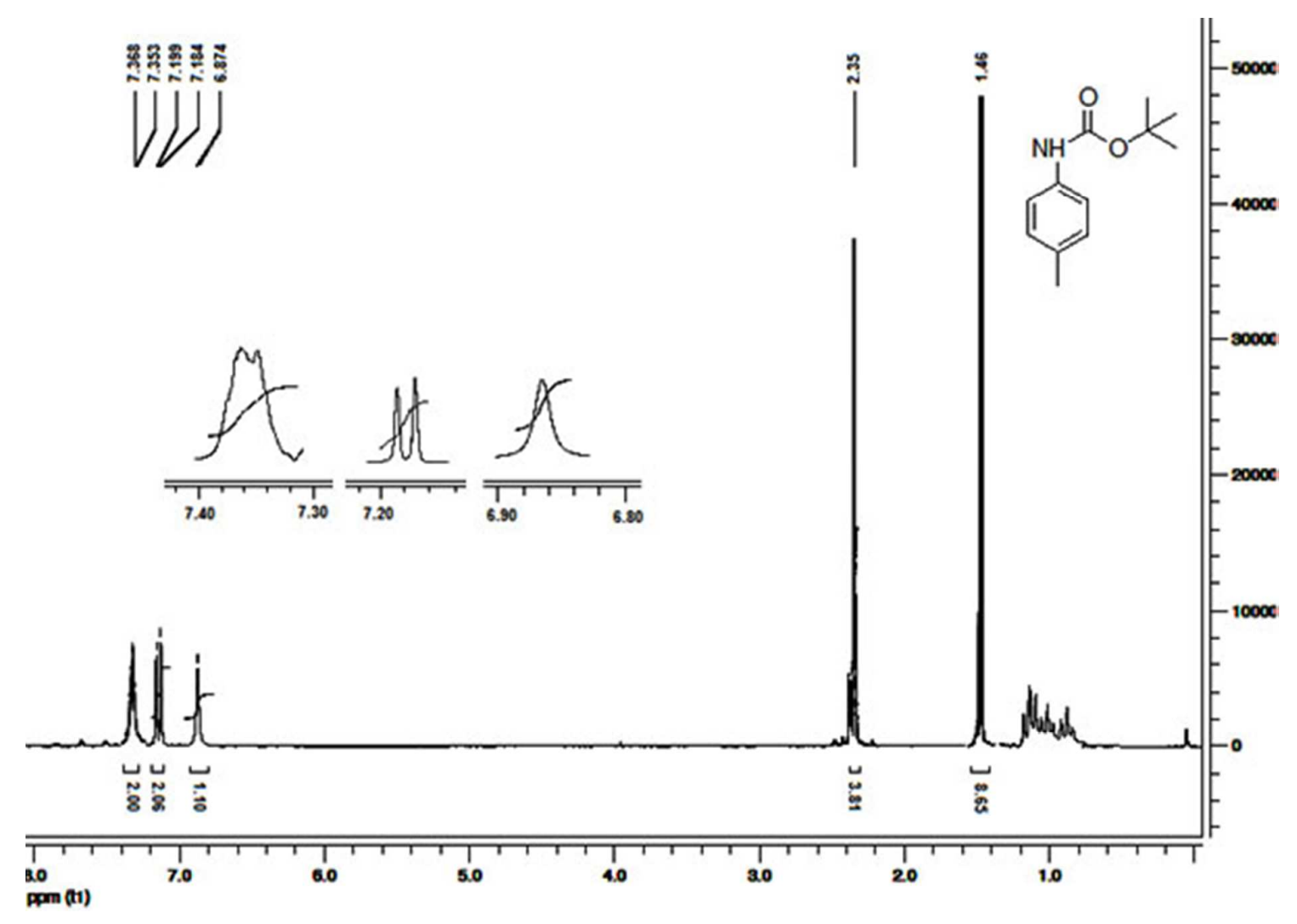

$t$-butyl $N$-(4-methylphenyl)carbamate (11) 


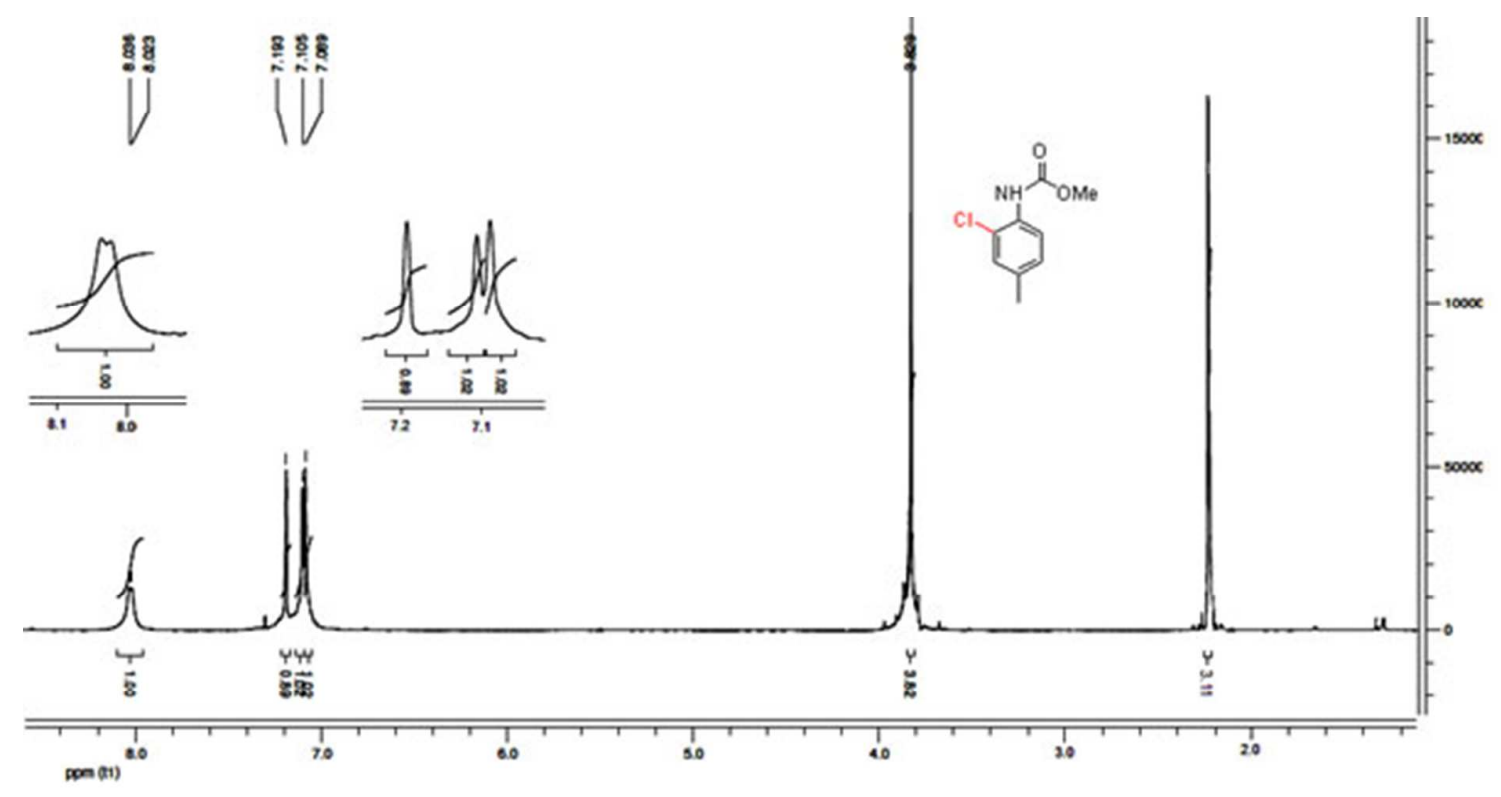

Methyl N-(2-chloro-4-methylphenyl)carbamate (12)

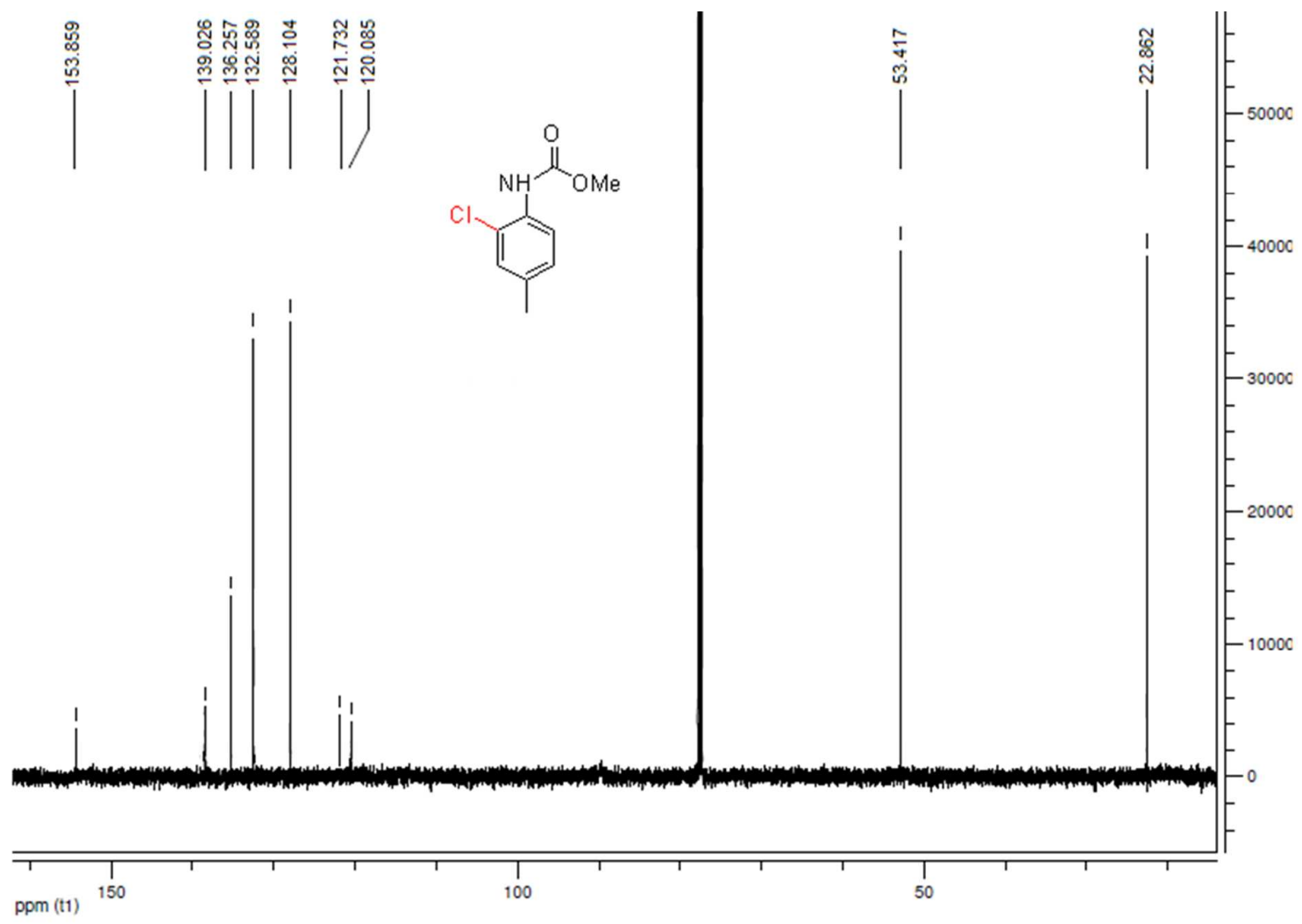

Methyl N-(2-chloro-4-methylphenyl)carbamate (12) 

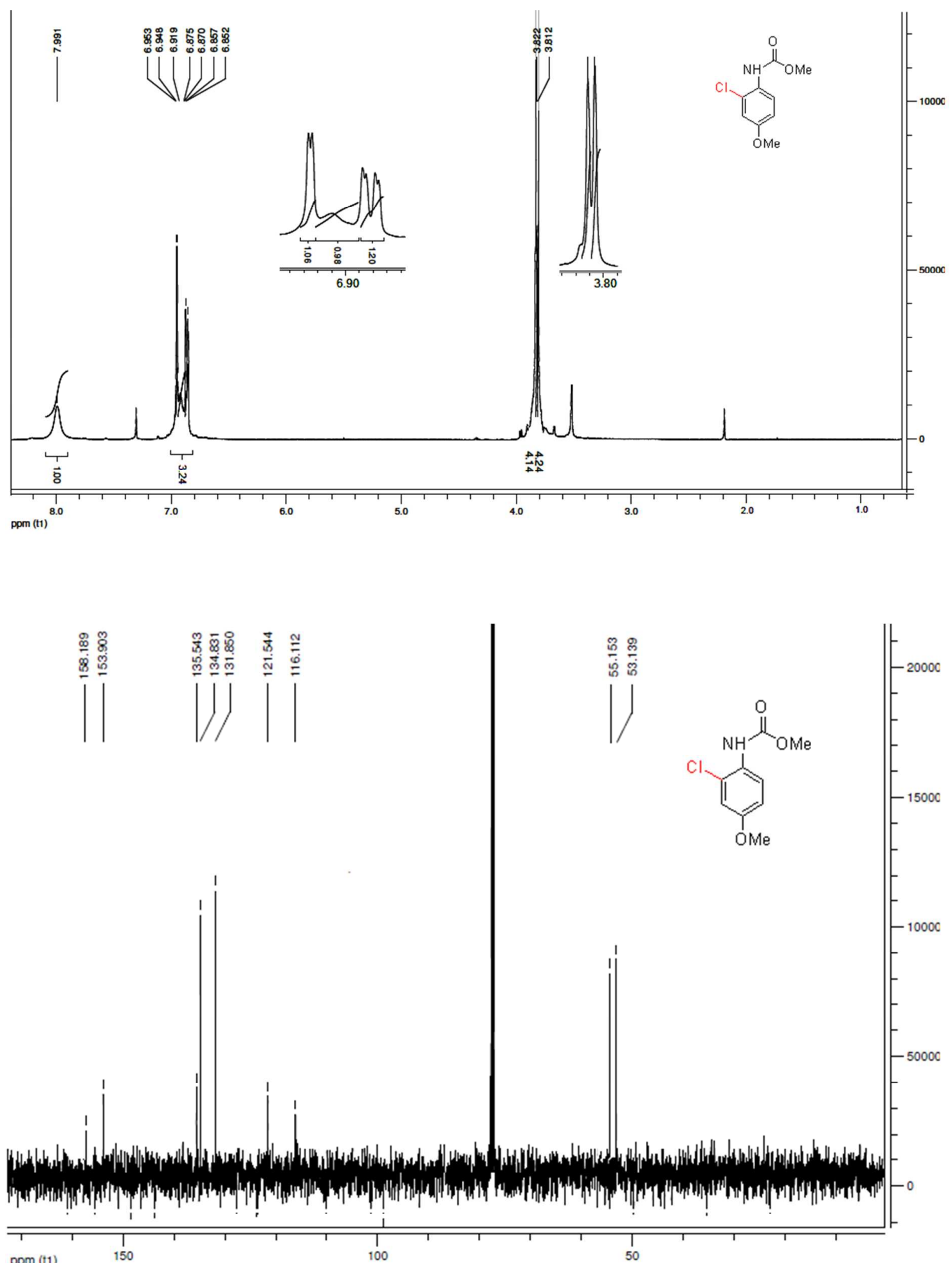

Methyl $N$-(2-chloro-4-methoxyphenyl)carbamate (13) 


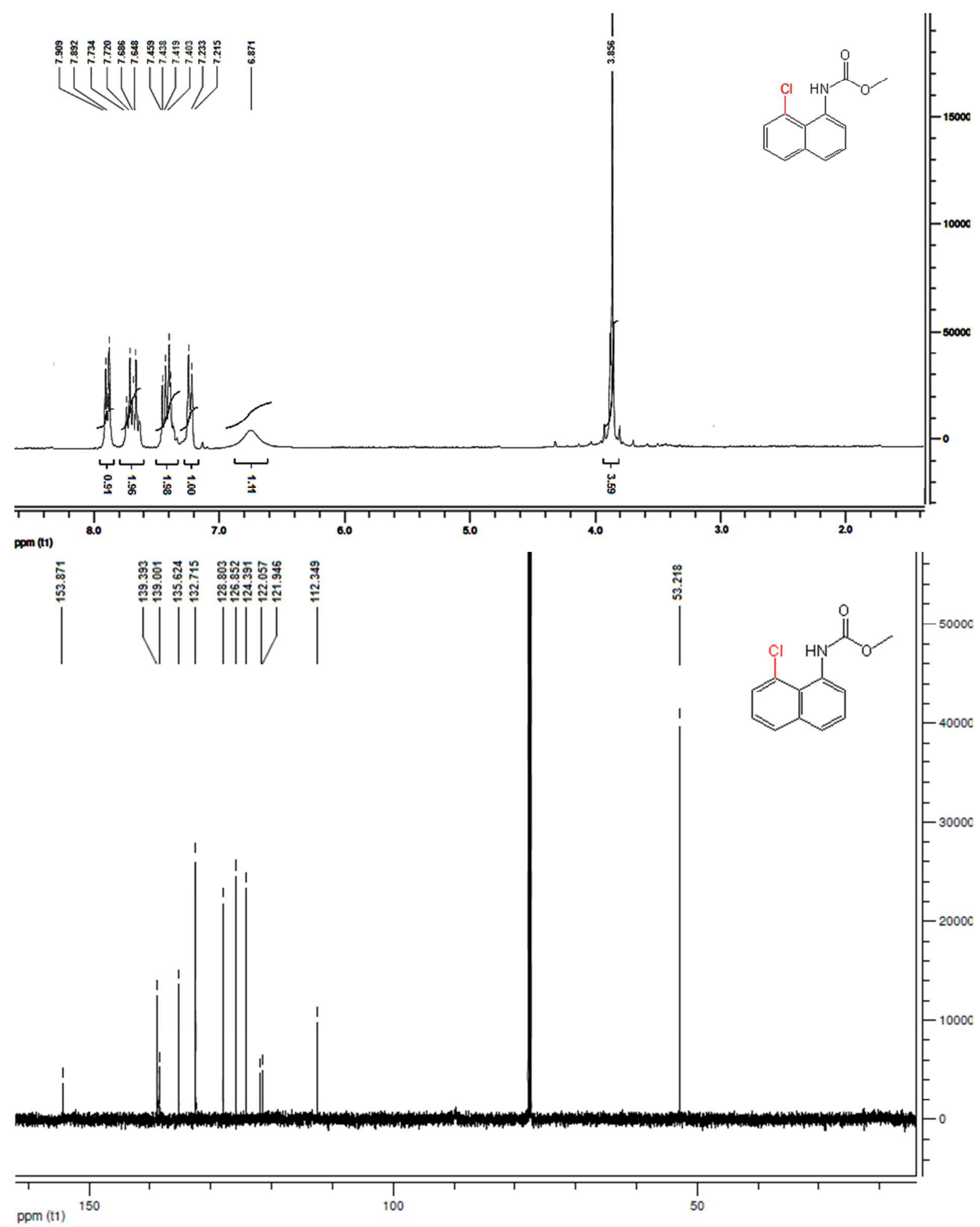

Methyl $N$-(8-chloro-1-naphthyl)carbamate (14) 

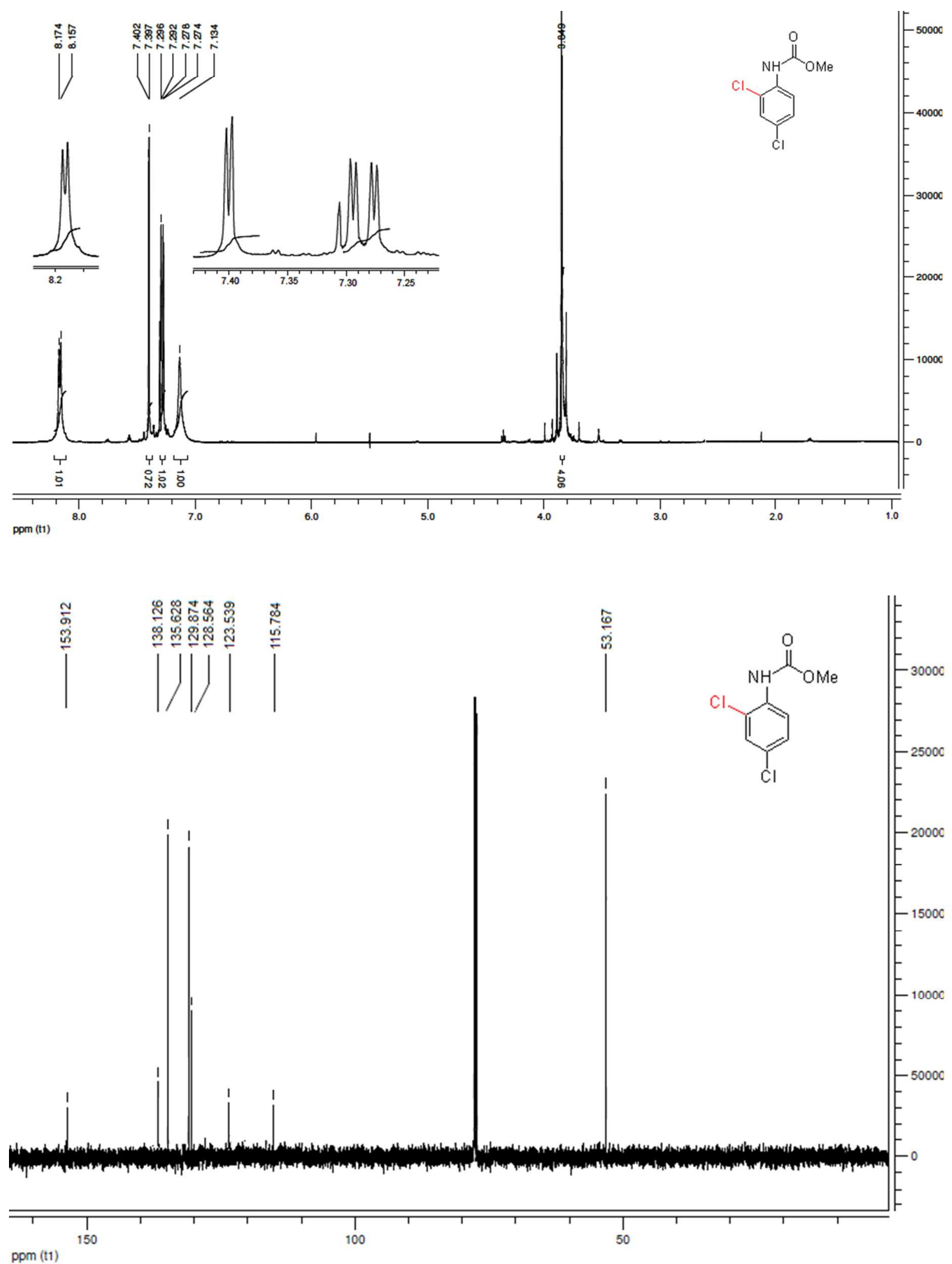

Methyl N-(2,4-dichlorophenyl)carbamate (15) 

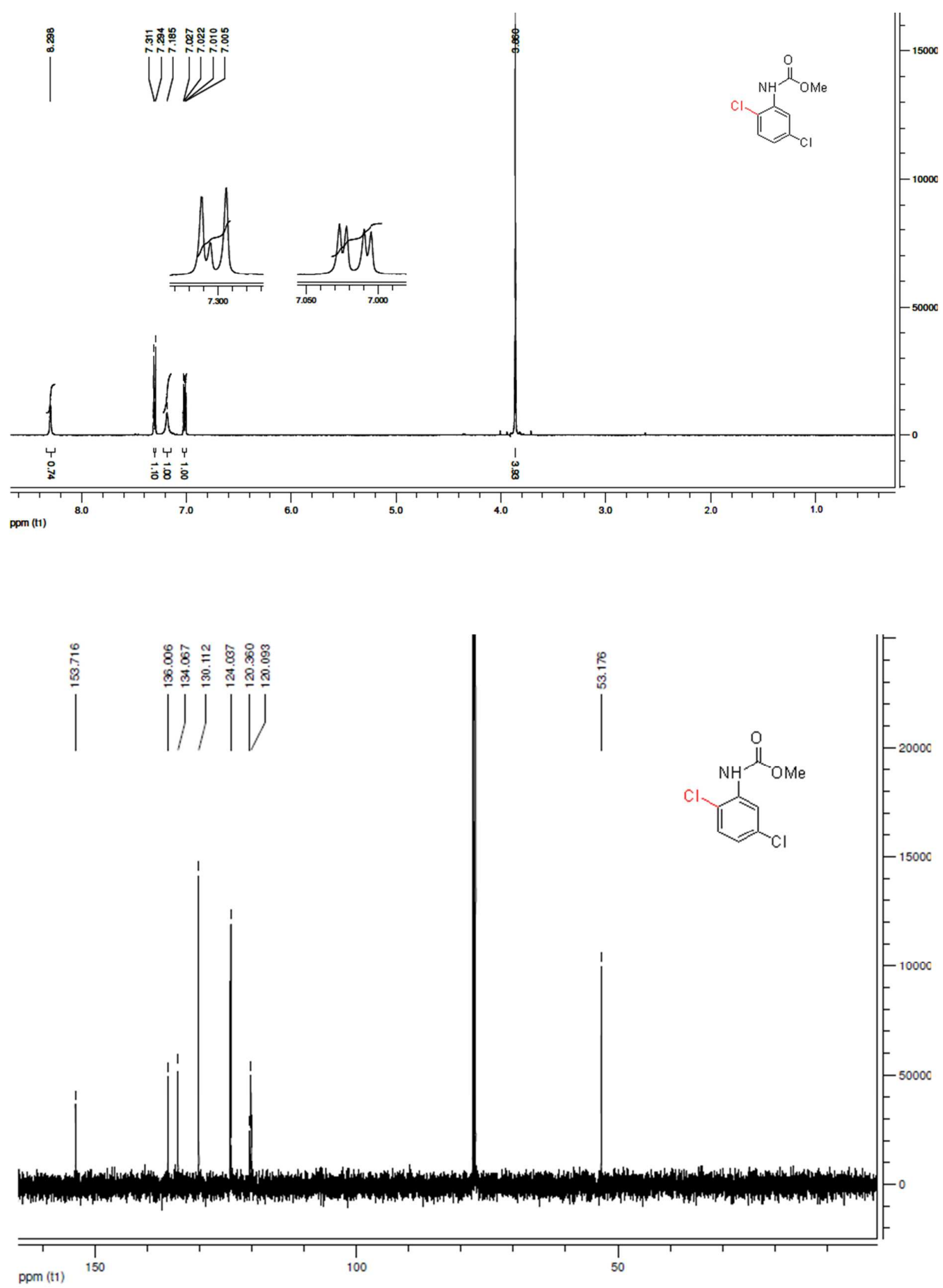

Methyl $N$-(2,5-dichlorophenyl)carbamate (18) 

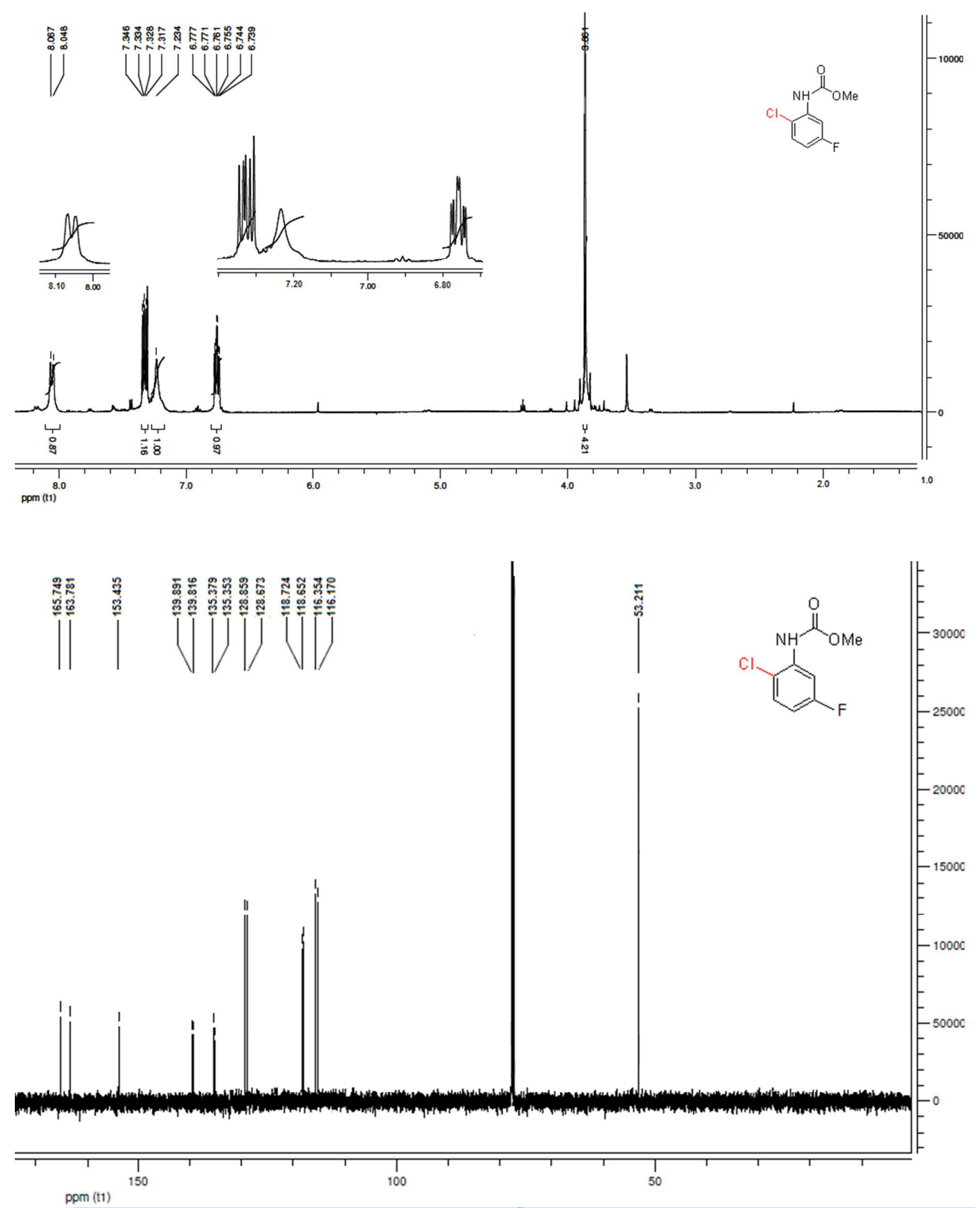

Methyl N-(2-chloro-5-fluorophenyl)carbamate (19) 

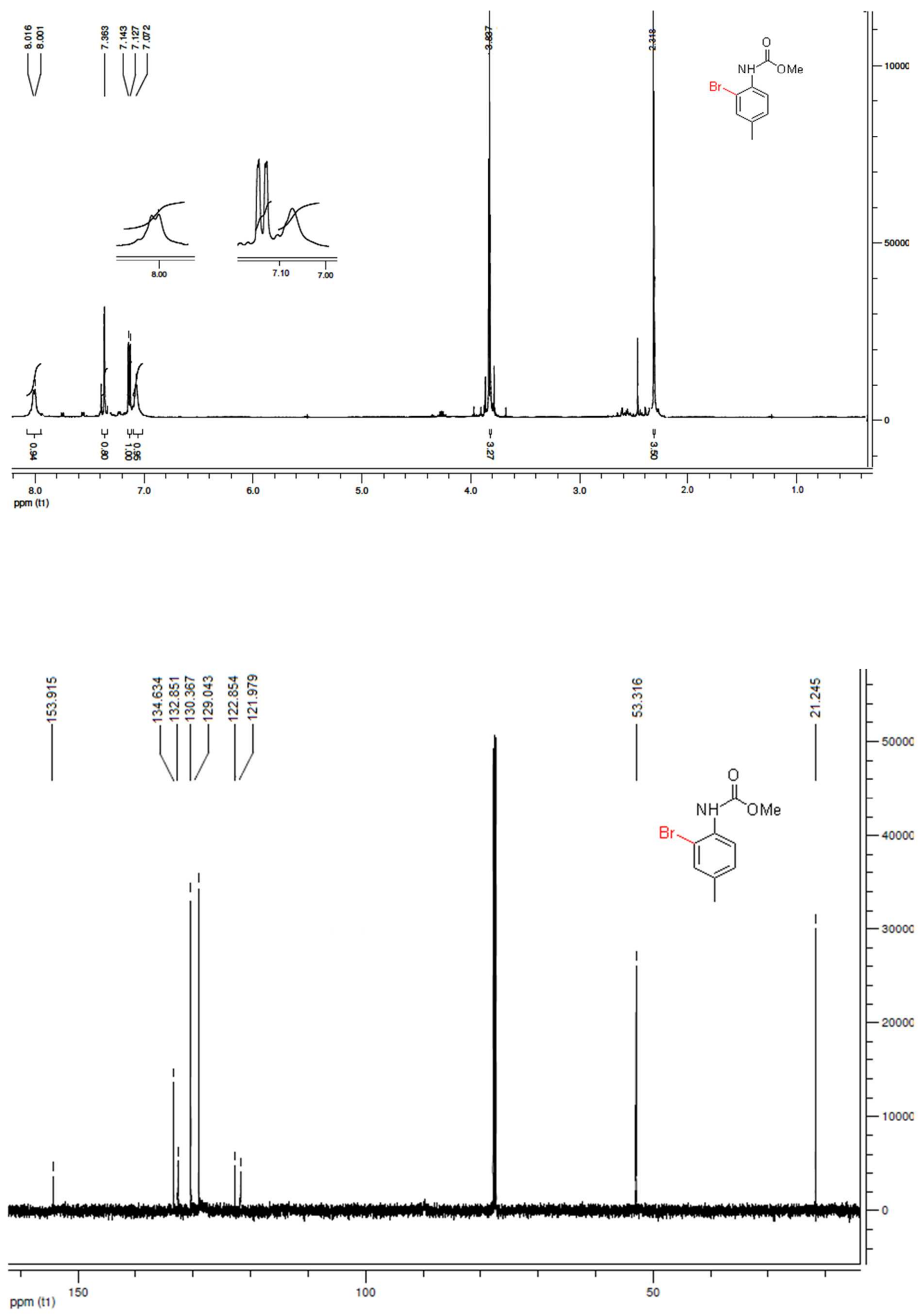

Methyl N-(2-bromo-4-methylphenyl)carbamate (20) 

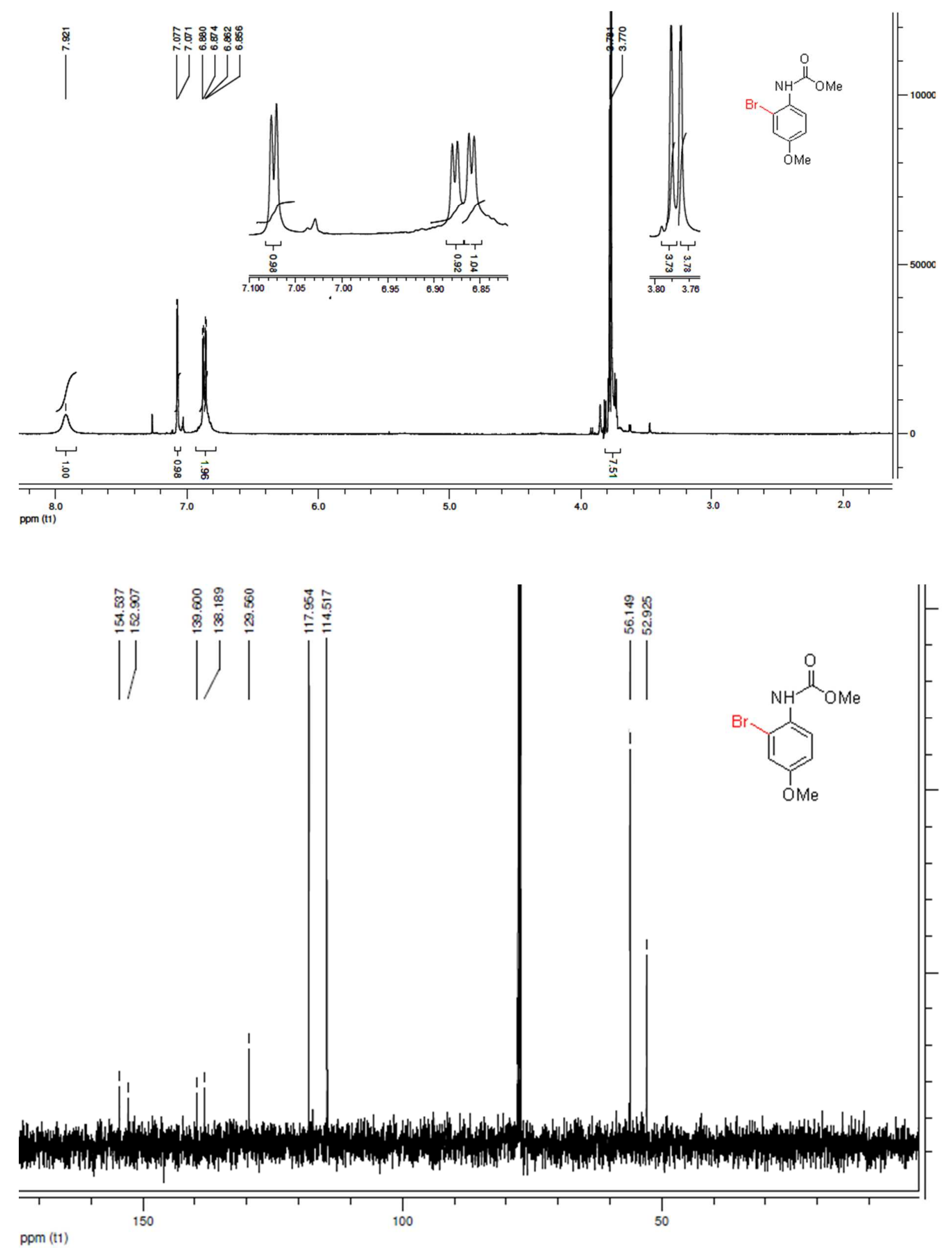

Methyl N-(2-bromo-4-methoxyphenyl)carbamate (21) 


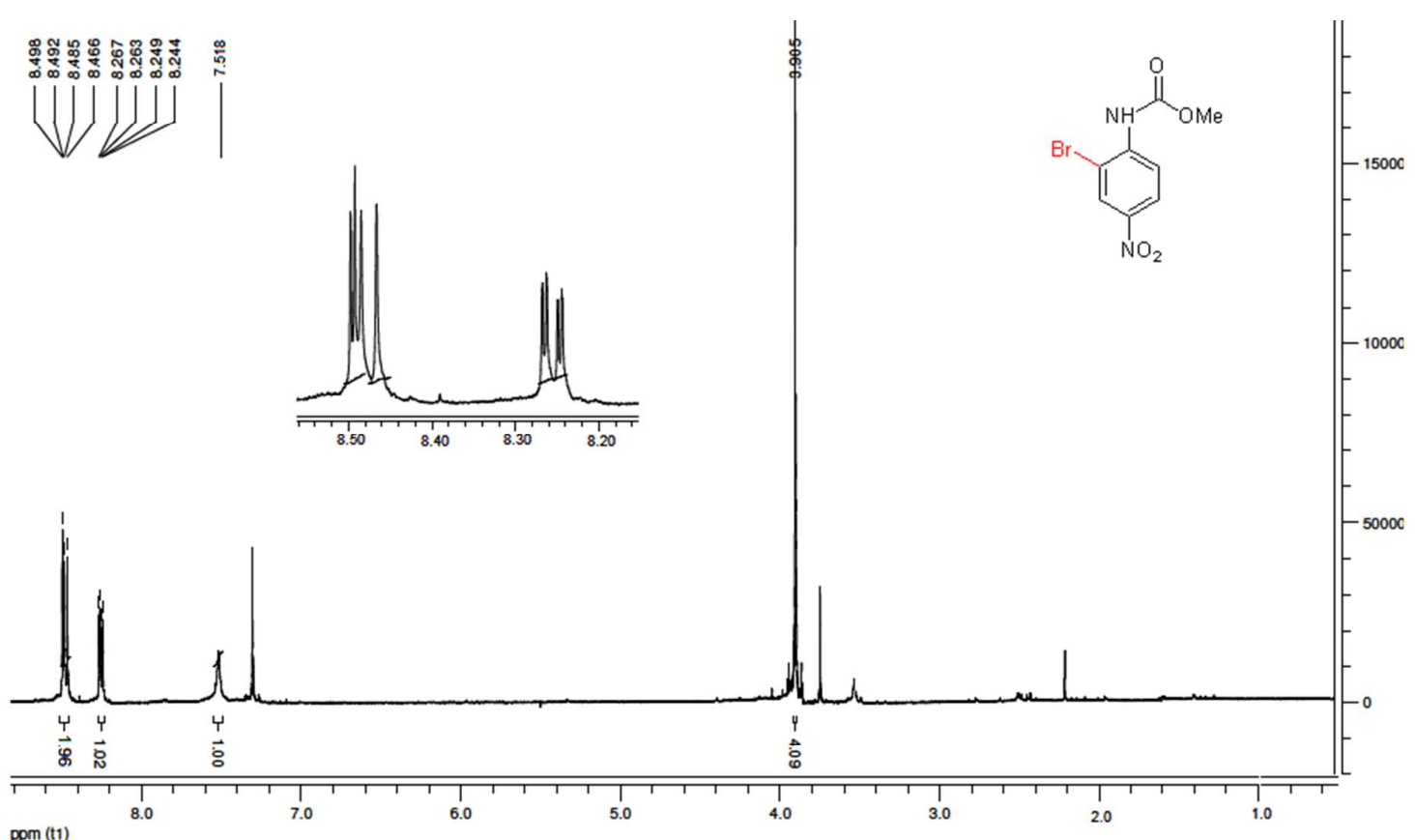

ppm (t1)

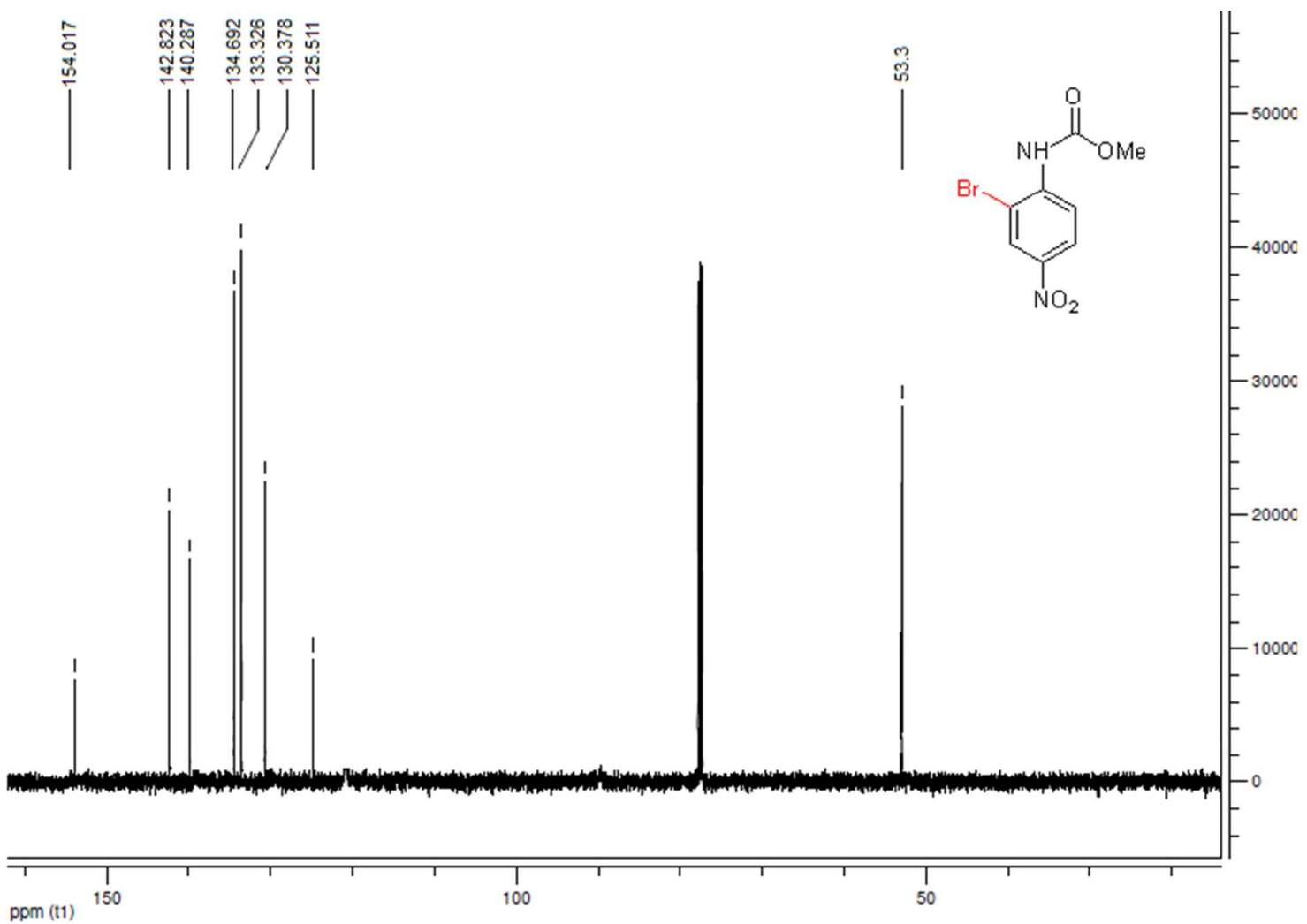

Methyl N-(2-bromo-4-nitrophenyl)carbamate (22) 

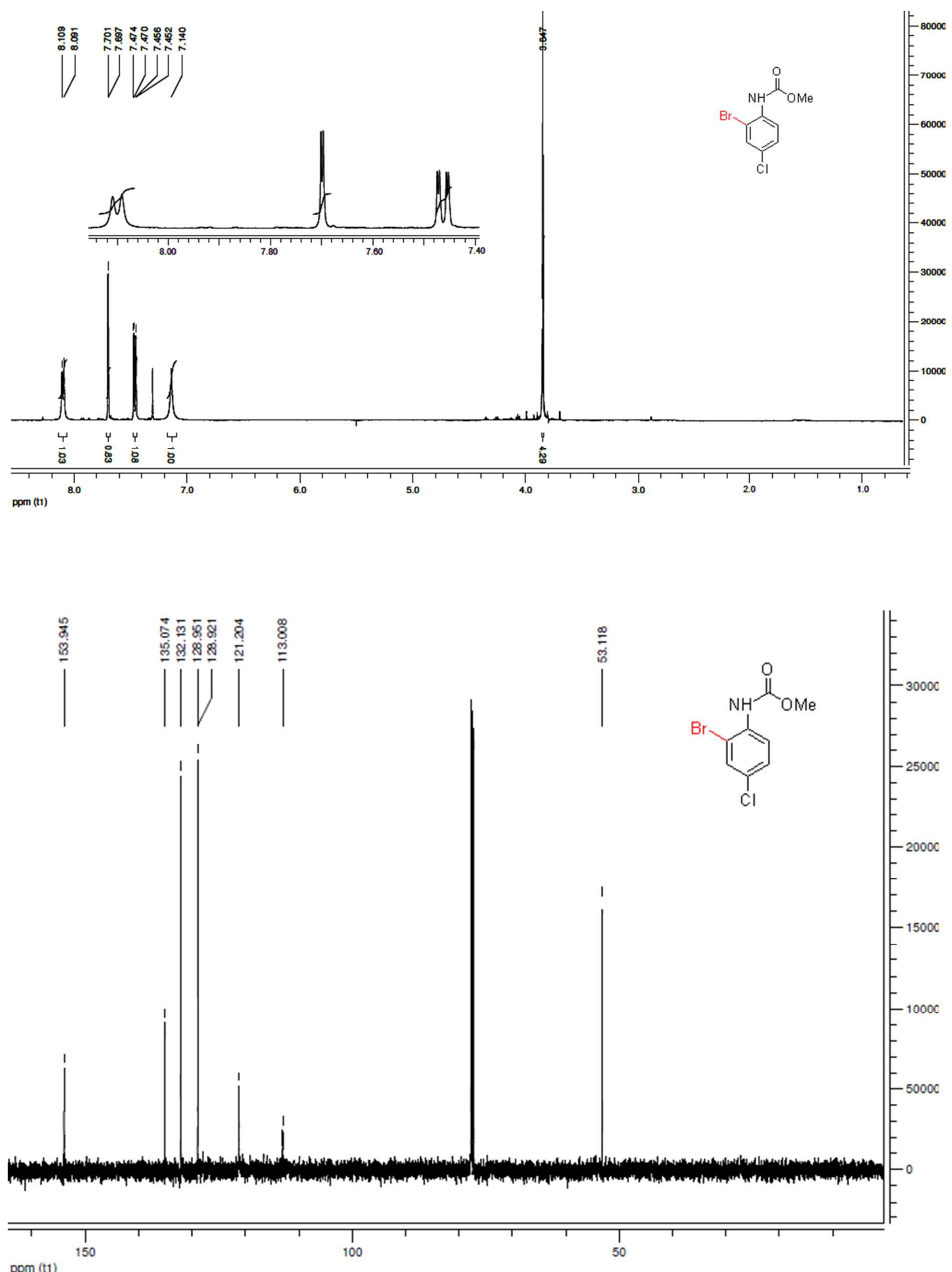

Methyl N-(2-bromo-4-chlorophenyl)carbamate (23) 

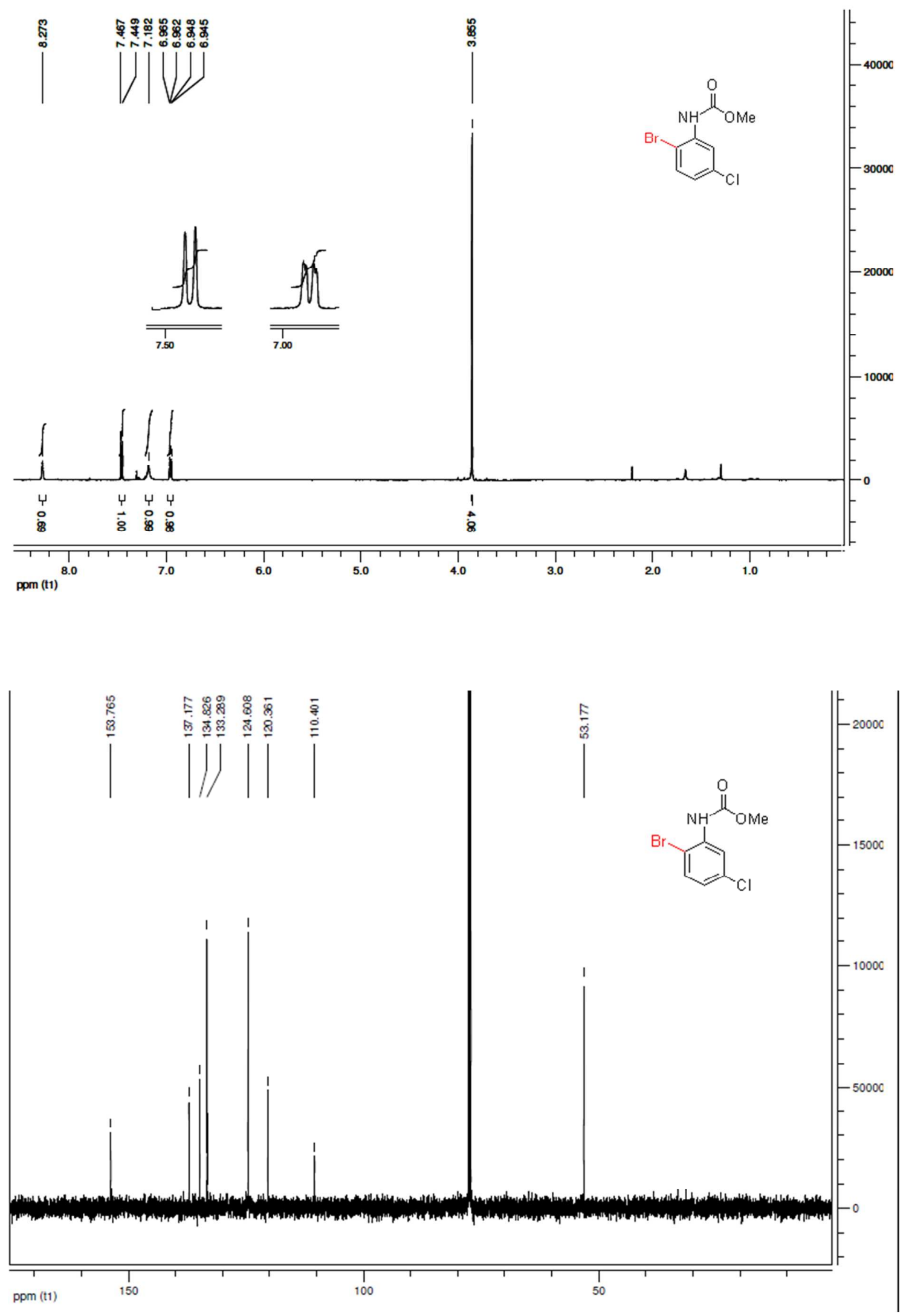

Methyl $N$-(2-bromo-5-chlorophenyl)carbamate (26) 


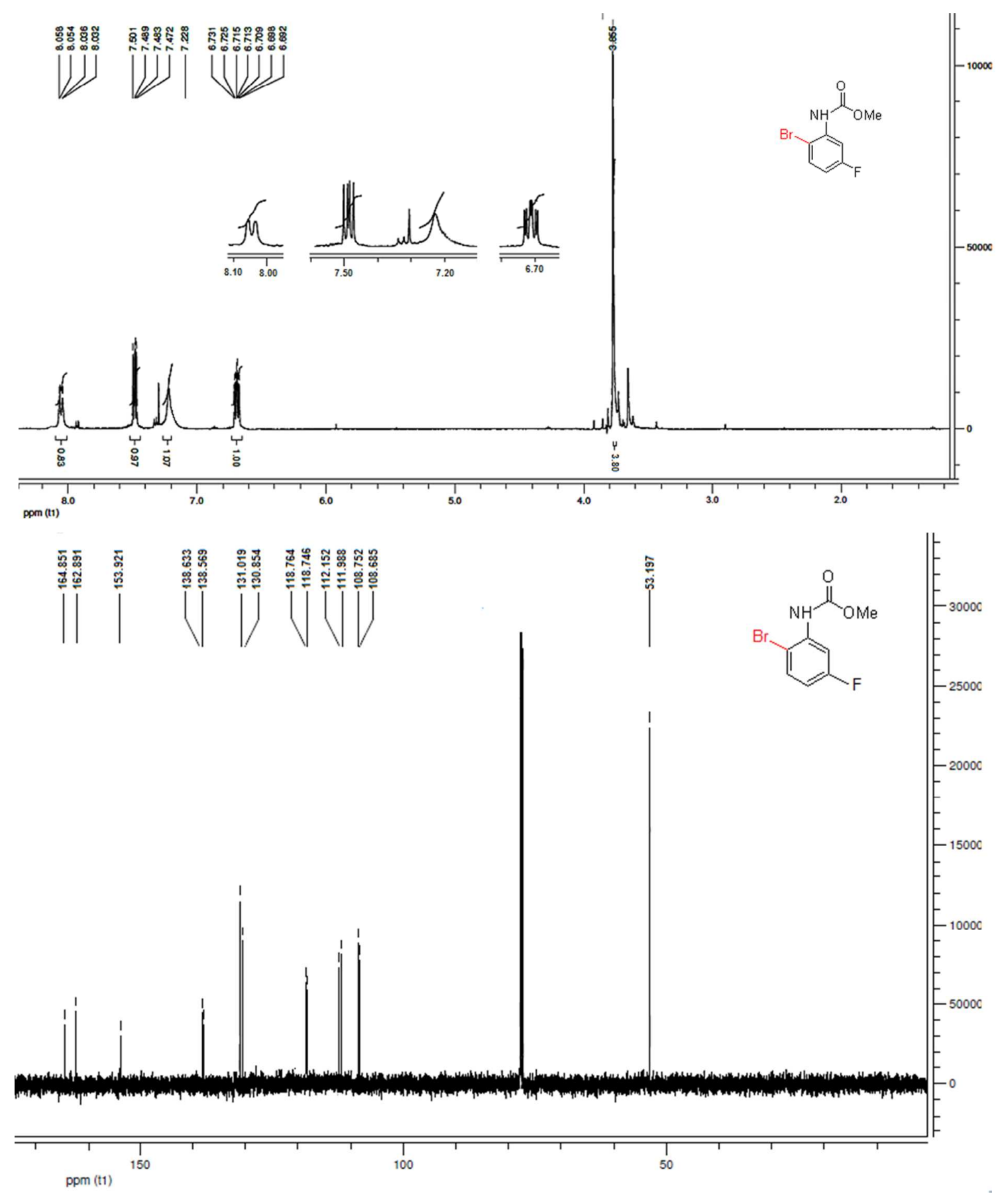

Methyl N-(2-bromo-5-fluorophenyl)carbamate (27) 


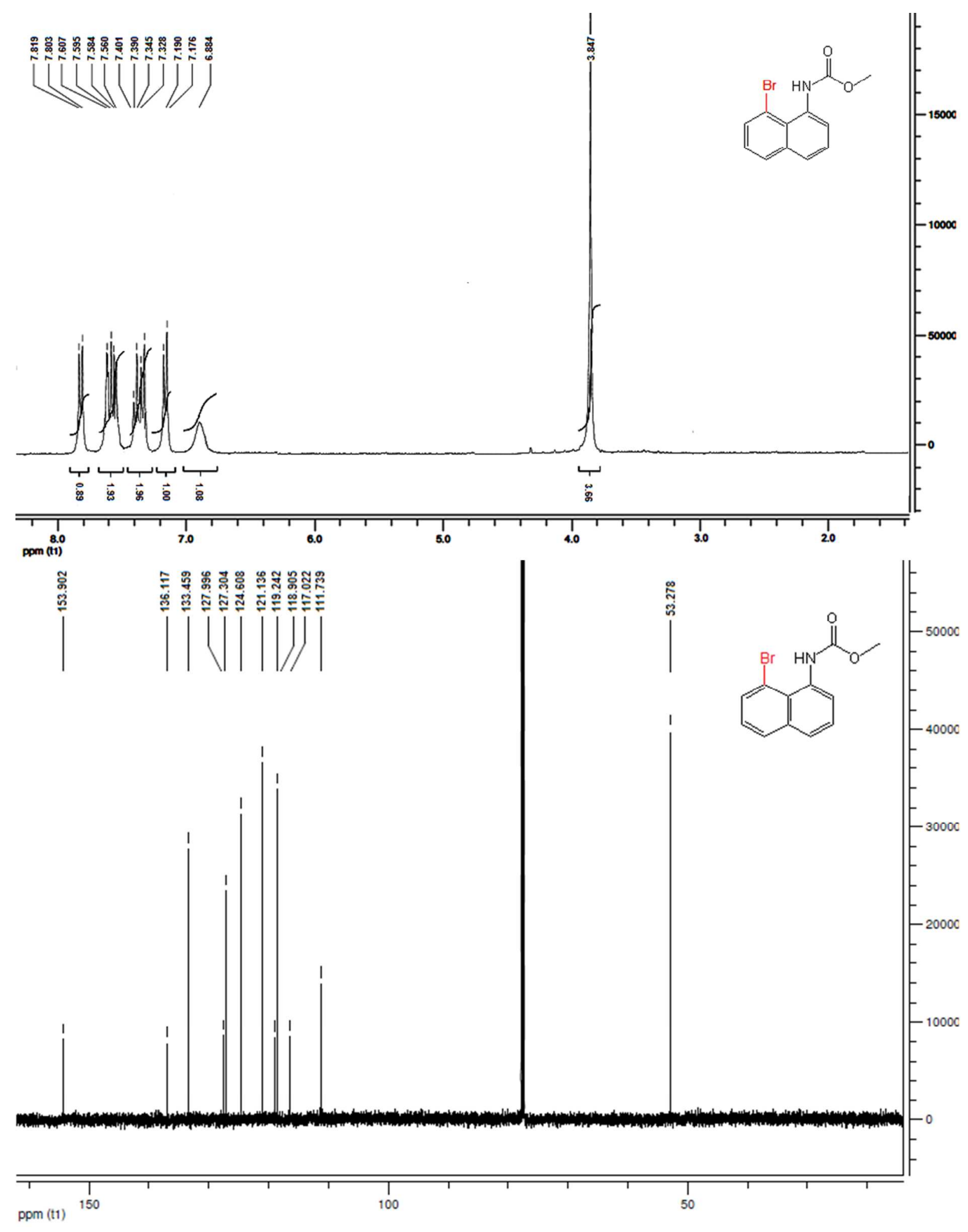

Methyl $N$-(8-bromo-1-naphthyl)carbamate (28) 

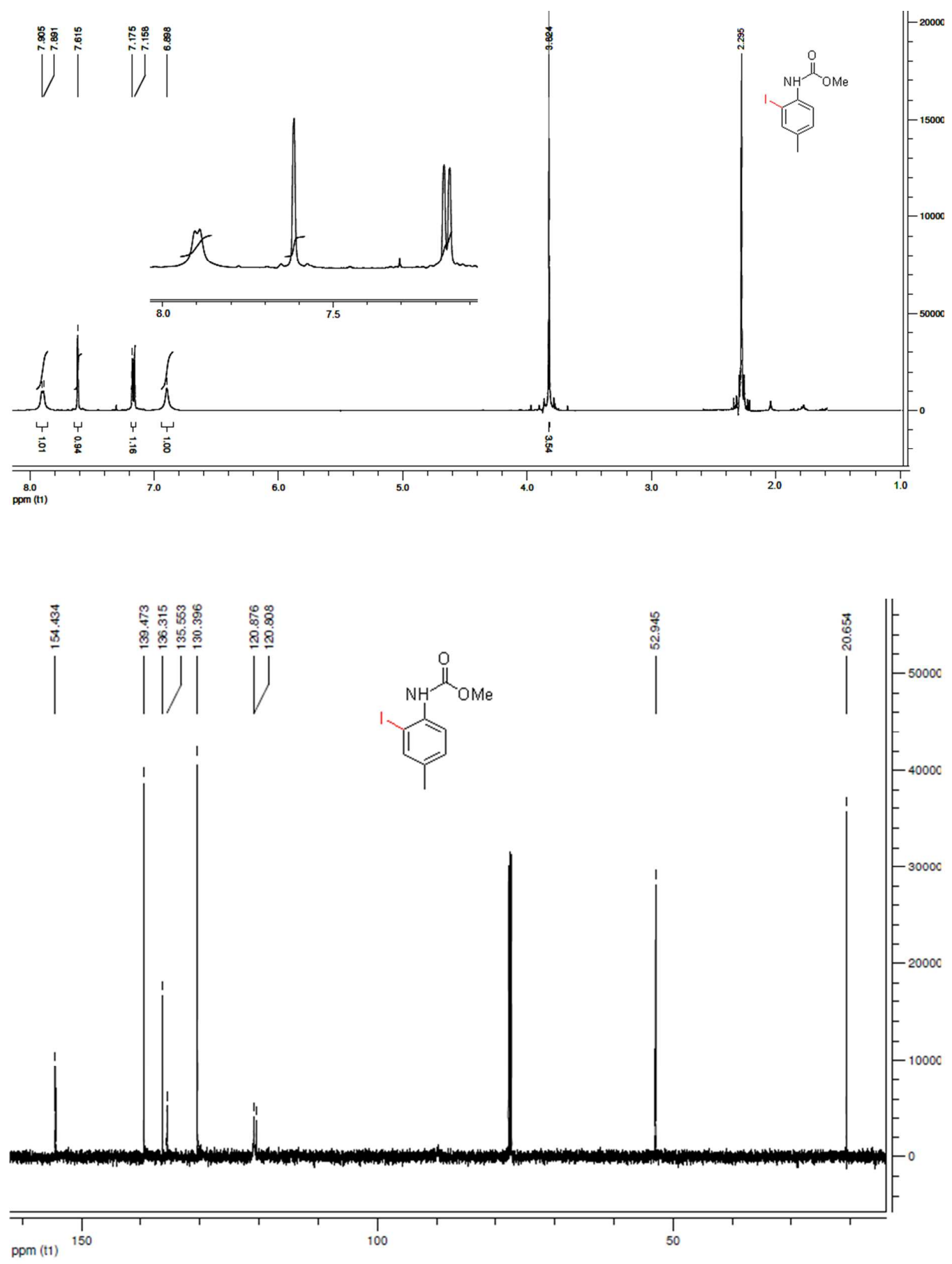

Methyl N-(2-iodo-4-methylphenyl)carbamate (29) 

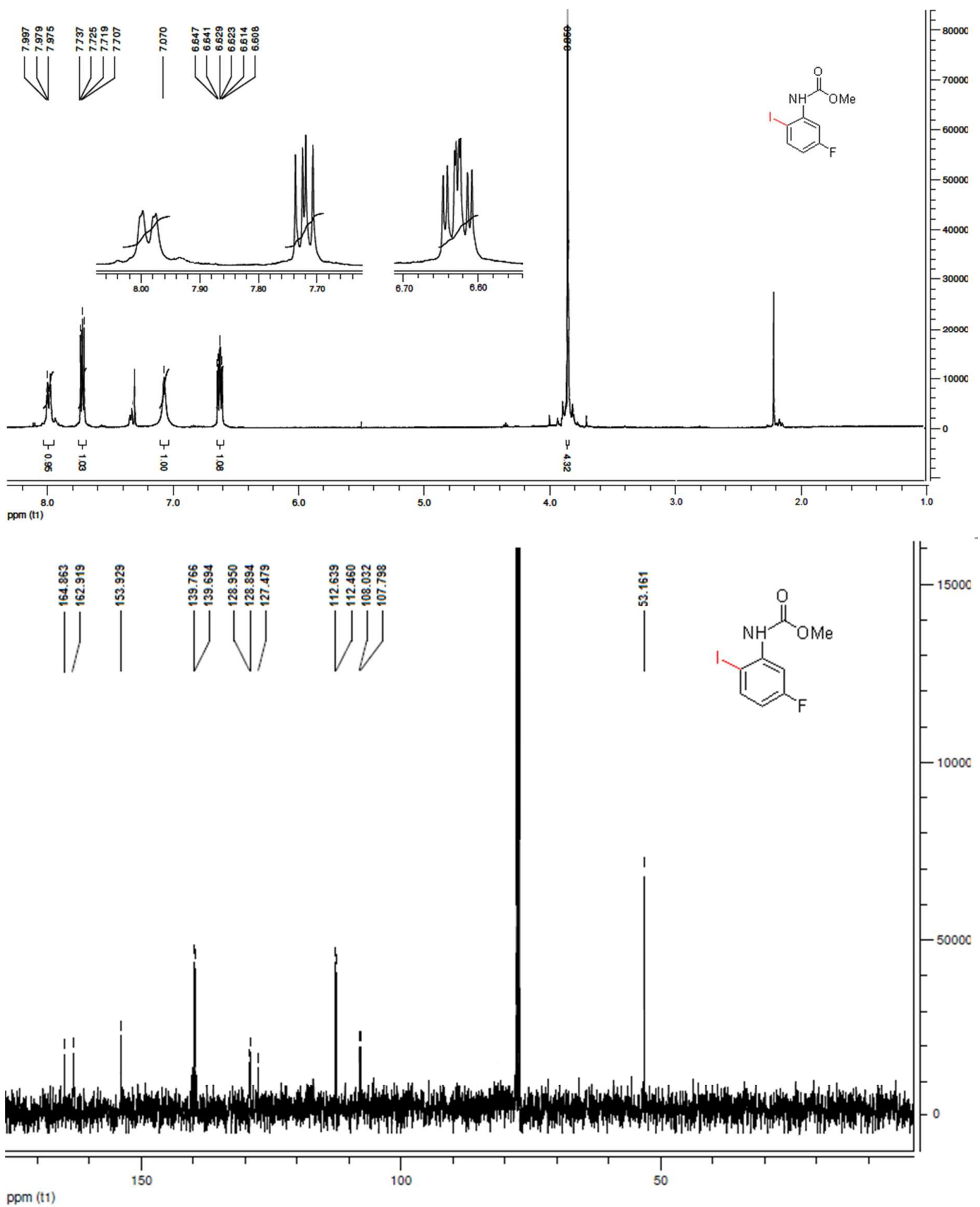

Methyl N-(5-fluoro-2-iodophenyl)carbamate (30) 

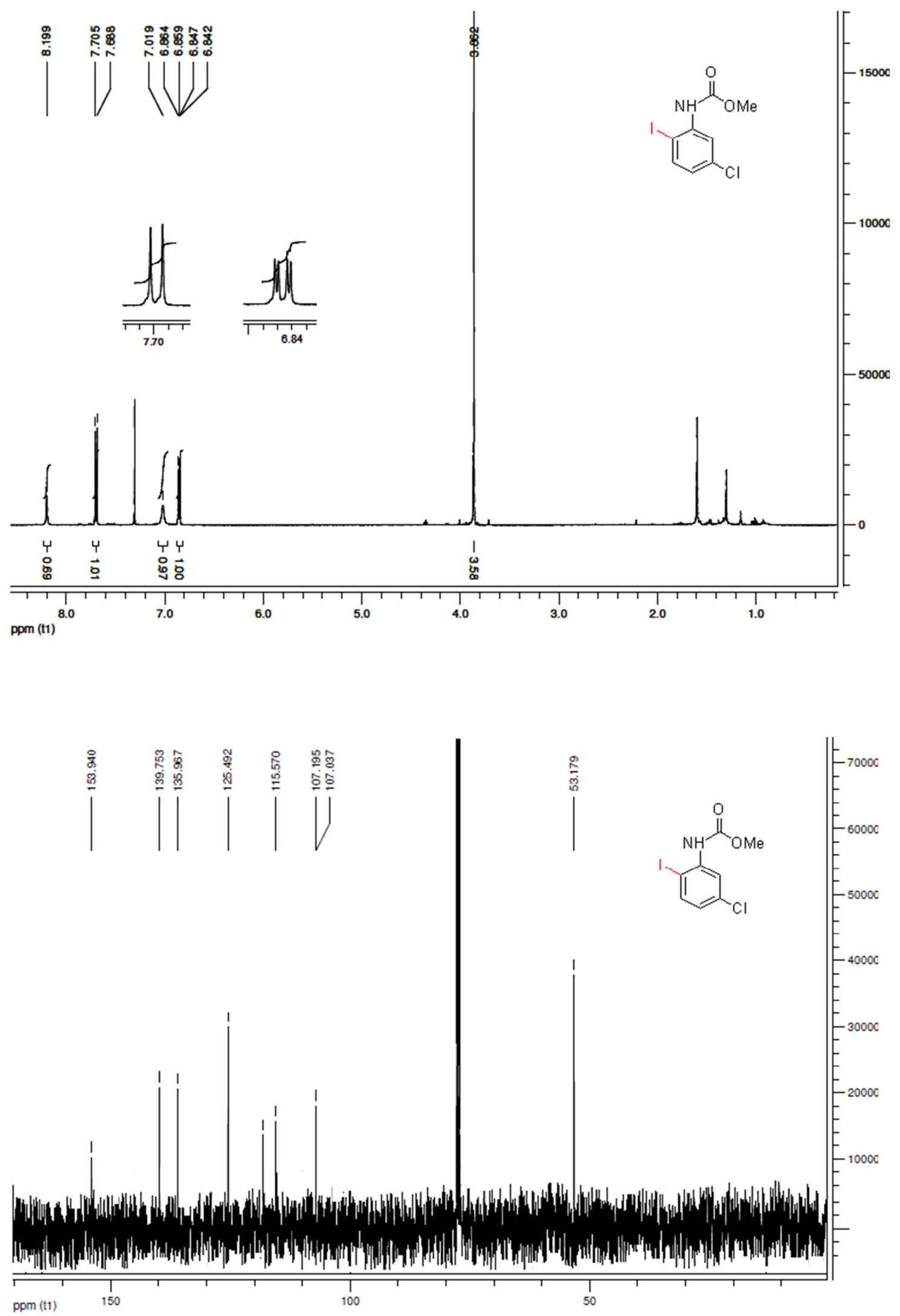

Methyl N-(5-chloro-2-iodophenyl)carbamate (31) 


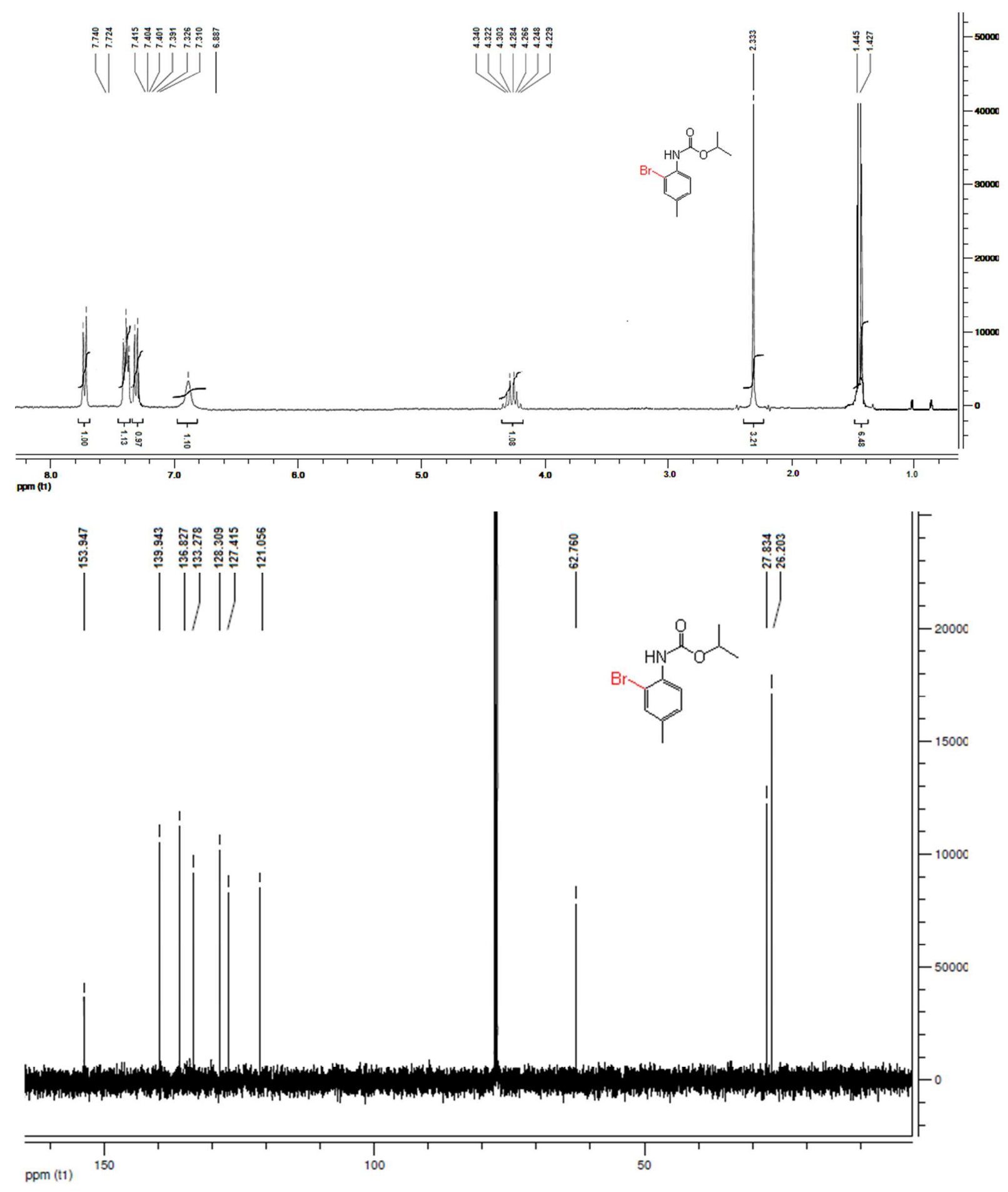

Iso-propyl N-(2-bromo-4-methylphenyl)carbamate (34) 


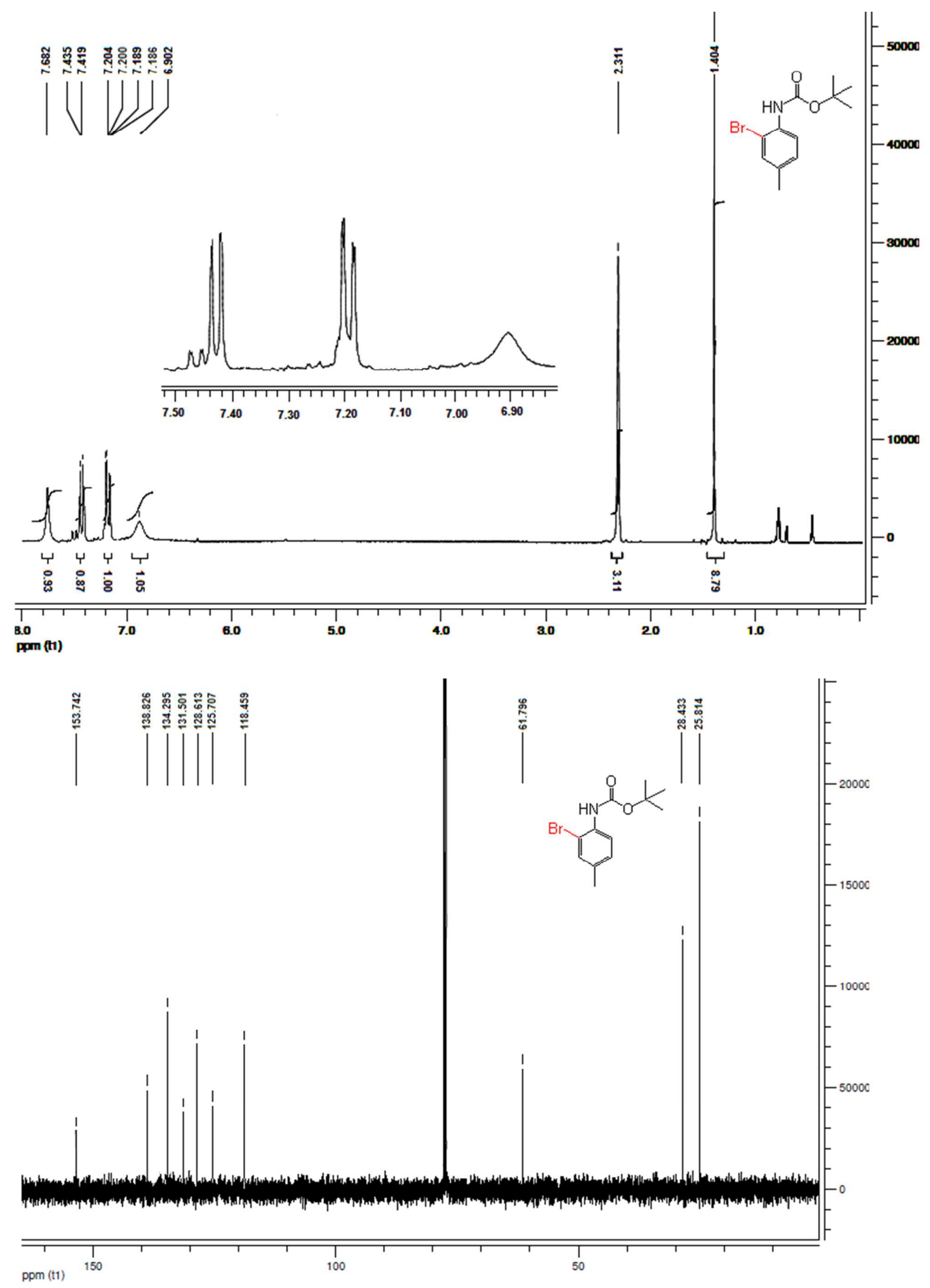

$t$-Butyl N-(2-bromo-4-methylphenyl)carbamate (35) 


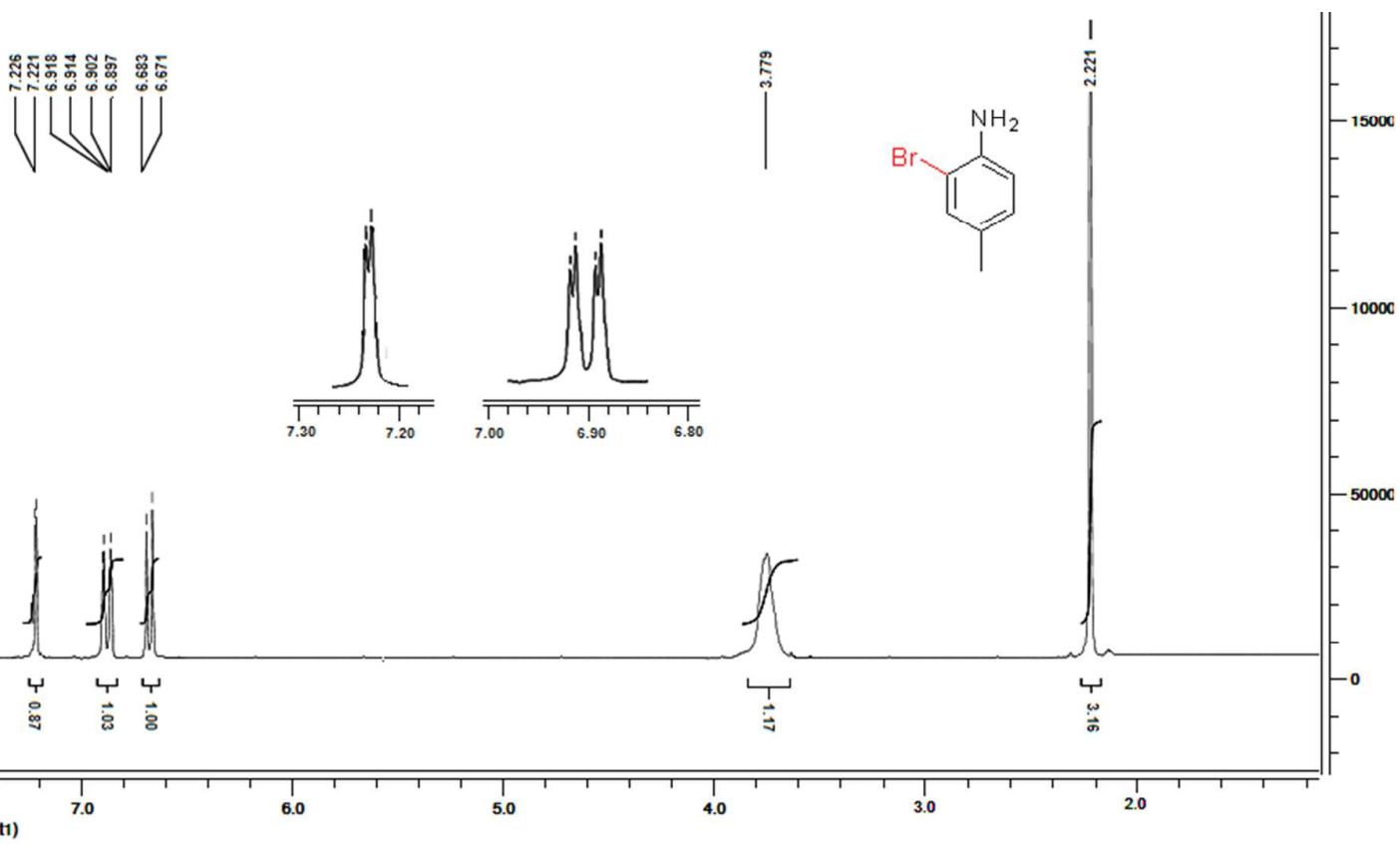

2-Bromo-4-methylaniline (36) 